\title{
1 An investigation of the flow properties of rutile 2 particles: fluidization behaviour linked with 3 shearing studies
}

\author{
Domenico Macrì $^{\mathbf{a}}$, Massimo Poletto ${ }^{\mathrm{b}}$, Diego Barletta ${ }^{\mathrm{b}}$, Paola Lettieri ${ }^{\mathrm{a}^{*}}$
}

${ }^{a}$ Department of Chemical Engineering, University College London, London WC1E 7JE, UK

${ }^{\mathrm{b}}$ Dipartimento di Ingegneria Industriale, Università degli Studi di Salerno, Via Giovanni Paolo II, 132-I-84084 Fisciano (SA), Italy

*Corresponding author, Tel: +44 (0)20 7679 7867,p.lettieri@ucl.ac.uk

\section{ABSTRACT}

The paper reports on part of an extensive experimental campaign aimed at studying the influence of operative conditions on the fluidization behaviour of industrial reactive powders. The fluidization behaviour of two different types of rutile particles, namely a synthetic and a natural rutile, was investigated at temperatures ranging from ambient up to $500{ }^{\circ} \mathrm{C}$. Their fluidization quality was also characterised through the bed collapse test, which provides a sensitive and discriminating methodology for the assessment of the changes in the materials' responses between low and high-temperature operation. The results obtained from the fundamental fluidization tests and bed collapse technique were linked to the rheological analysis of the flow properties of the materials. The comparison underpinned the relative role of the interparticle forces and the hydrodynamic forces on the flow behaviour of the particles at process conditions.

\section{INTRODUCTION}

Fluidized bed reactors are used in a wide range of industrial chemical processes, and they are particularly useful in high-temperature systems thanks to their ability to provide high heat transfer rates and rapid solids mixing which lead to isothermal and more controllable conditions. Their applications spread the environmental, chemical, energy and process industries. For example, they are a key technology in the petroleum industry, catalytic chemicals synthesis processes, combustion and gasification of solid fuels (coal, wastes and biomass), metals productions and many more [1-5].

However, despite the countless researches that have been done so far [6-12], a satisfactory understanding of the phenomena that are responsible for changes in the behaviour of 
reported by various authors in their reviews on the subject [13-15], the findings of the studies on the influence of temperature on fluidization are still controversial. The dispute is still unsolved as the relative role of the hydrodynamic forces (HDFs) and the interparticle forces (IPFs) on the flow behaviour of the powders at process conditions is open-ended. Moreover, the uncertain nature and the lack of a direct measuring methodology of the IPFs enhance such a controversy.

Some authors approached the problem of measuring the IPFs involved by introducing them in a controlled manner with the addition of a liquid phase to Geldart group B and A materials [16]. They monitored the changes in the fluidization behaviour of such powders and demonstrated how the presence of liquid, combined with the effect of increasing the temperature, enhanced the role of IPFs causing the shift to a typical group $\mathrm{C}$ behaviour.

Other authors suggested a multidisciplinary approach based on linking rheological and fluidization tests with the aim of understanding and quantifying the effect of IPFs on fluidized powders [17-24]. Further work is, however, needed; the challenge lies in the difficulty to relate the different rheological measurements to fluidization, mostly due to the variety of techniques employed, which makes standardisation of rheological tests very difficult.

Another methodology widely used to assess the flow properties of powders at various operative condition is the bed collapsing test (BCT), which provides a quantitative measurement of testing the capacity of a powder bed to retain aeration gas [25]. Such a test consists of suddenly turning off the gas supply to a vigorously bubbling fluidized bed and recording the deflation of the bed with time. It has been adopted to compare Geldart Group A and $\mathrm{C}$ powder behaviour [26], to assess the effects of fines distribution [27-29], to evaluate changes in catalyst properties and to help diagnose commercial operational problems [30], but mostly to characterise dense phase properties [31-38].

Barreto et al. [33] found good agreement between the results for the dense phase voidage in bubbling beds obtained using the BCT technique and those directly observed with the Xrays absorption technique.

Lettieri at al. [39-41] and Formisani et al. [35-37] used the bed collapse technique to investigate the influence of temperature on the dense phase properties of various solid materials. Lettieri and collaborators observed that, despite the sensitivity of the fluidization parameters on the initial gas velocity, it did not affect the trends of these parameters with 64 increasing temperature. This finding suggests that as long as the experiments are carried out in a consistent fashion, i.e. at the same initial fluidizing velocity, a meaningful assessment of 
the influence of process conditions can be achieved. In addition, they found that the standardised collapse time (SCT) was the most discriminating parameter to distinguish between systems of powders dominated by the interparticle forces or the hydrodynamic forces. The SCT increased with increasing temperature for those powders dominated by the HDFs, while it decreased with increasing temperature for those materials for which the increasing influence of the IPFs caused formation of aggregates within the bed. Formisani and co-workers highlighted the significant influence of operating temperature on the quality of bubbling and in particular on the "bubble hold-up", i.e. the deviation of the bed height in bubbling regime with respect to the extrapolated dense phase height. Their results indicated that the bubble hold-up increases with increasing temperature, because of the decrease in the gas velocity through the dense phase and in the bubble diameters. The authors linked these phenomena to the thermally induced IPFs, which enhanced the cohesiveness of the dense phase, making the behaviour of the bed very similar to that typical of the beds of fine particles fluidized at room temperature.

Geldart and co-workers [42,43] also reported that the BCT parameters could be influenced by the starting fluidizing velocity and they found that the voidage is strongly affected by particle density and size distribution, as well as by variations in gas viscosity and density.

This work is part of an extensive experimental project (see [44]) aimed at assessing the effect of high temperature on the flow properties and fluidization behaviour of several industrial reactive powders. To this end, a twofold approach, based on fundamental fluidization and rheological measurements, was followed with the aim of evaluating how the particle-particle interactions change with temperature.

On the one hand, the fluidization behaviour of each powder has been studied at process temperatures ranging from ambient up to $500{ }^{\circ} \mathrm{C}$ in a specially designed heated fluid-bed reactor. Fundamental fluidization tests were performed using the unique X-ray Imaging technique available at University College London (UK), which enabled to visualise the internal flow pattern inside the reactor and to obtain quantitative information on voidage distribution, bed expansion, mixing and segregation within the fluidized bed.

On the other hand, the unique heated annular shear cell available at the University of Salerno (Italy) has been used to assess the changes of the bulk flow properties of the different types of titanium ores at ambient and with increasing temperature. These experiments highlighted a significant increase with temperature of the macroscopic bulk flow properties, such as unconfined yield strength and cohesion, which resulted in a lower flowability of the samples. In parallel, two different models were used to correlate the experimental results with 
100

101

102

103

104

105

106

107

108

109

110

111

112

113

114

115

116

117

118

119

120

121

122

123

124

125

126

127

128

129

130

the microscopic interparticle interaction forces. The shear testing results, reported in $[45,46]$, provided an indication of the ability of the powders to flow and underpinned the link between the fluidization and the rheological behaviour below the minimum fluidization conditions: the capability of the powders to fail under a certain load will be directly correlated to their capability to attain fluidization.

\section{MATERIALS AND METHODS}

\subsection{Experimental materials and setup}

The main physical properties of the two investigated materials, synthetic (SR) and natural (NR) rutile, are reported in Table 1. It includes particle densities $\left(\rho_{\mathrm{p}}\right)$, bulk densities $\left(\rho_{\mathrm{b}}\right)$, Sauter mean diameters $\left(\mathrm{d}_{\mathrm{sv}}\right)$, particle size distributions (PSD) and relative diameter spread $\left(\operatorname{RDS}=\left(\mathrm{d}_{84}-\mathrm{d}_{16}\right) /\left(2 \mathrm{~d}_{50}\right)\right.$. RDS is defined according to Geldart [47] by using the $16^{\text {th }}$, the $50^{\text {th }}$ and the $84^{\text {th }}$ percentile sizes $\left(\mathrm{d}_{16}, \mathrm{~d}_{50}\right.$ and $\mathrm{d}_{84}$ respectively) obtained from sieve analysis. It is used to compare the width of the size distribution of the powders provided for this work. Details on the bulk flow properties of the materials, as well as images taken by mean of a scanning electron microscope and results from thermal gravimetric and differential analysis (TGA/DTA), can be found at references $[45,46]$.

A schematic drawing of the experimental rig and the X-ray facility used for this study is presented in Figure 1, for a detailed flow and control diagram please refer to [39].

The reactor used for testing the powders for temperatures up to $500^{\circ} \mathrm{C}$ is an Inconel vessel $100 \mathrm{~cm}$ tall with an internal diameter of $14.6 \mathrm{~cm}$ and a wall thickness of $3 \mathrm{~mm}$. The vessel is fitted with a very fine (i.e. pore size of $20 \mu \mathrm{m}$ ) stainless steel sintered distributor plate to ensure a high-pressure drop and therefore a good and even fluidization in the bed. The Inconel plenum chamber below the distributor plate (windbox) is $15 \mathrm{~cm}$ tall and it is packed with $10 \mathrm{~mm}$ ceramic balls to improve heat transfer. A $2.5 \mathrm{~kW}$ powered preheater $(10 \mathrm{~cm}$ diameter x $30.5 \mathrm{~cm}$ length) is installed on the gas feeding line, allowing an operating temperature up to $500{ }^{\circ} \mathrm{C}$.

The fluidizing gas used is compressed and desiccated air. It is measured with rotameters before being preheated while passing through the preheater and the windbox section, which is wrapped with $800 \mathrm{~W}$ heating tape. High temperatures in the vessel are achieved and maintained by means of two flexible ceramic heaters wrapped around it, and capable of providing operating temperatures up to $1250^{\circ} \mathrm{C}$. The two ceramic heaters cover $90 \mathrm{~cm}$ of the 
vessel height. Since this material is not transparent to X-rays, they are fitted to leave a vertical window, $7 \mathrm{~cm}$ wide, on both sides of the vessel, to let X-rays through. The hot surfaces are perfectly insulated using two layers of $1.5 \mathrm{~cm}$ thick super-wool, covered by a $7 \mathrm{~cm}$ thick layer of rock wool wrapped with silver tape.

A Rosemount differential pressure transducer, Model 1151, is used to measure the pressure drop profile as a function of the fluidizing gas velocity to determine the experimental minimum and complete fluidization velocities. A system of thermocouples allows temperature monitoring in various spots of the system, including inside and outside the reactor, the windbox and the feeding line. Indicators for temperatures in the bed, hightemperature alarms and bed pressure drop are displayed on a panel external to the electrical control box and directly linked to a data acquisition board (DAQ) that enables real-time information to be visualised and recorded on a computer. A specific software application was developed on purpose in the LabVIEW environment (National Instrument).

Two solenoid valves are fitted on the rig: SV1, for cutting the air supply to the bed, and SV2, for venting the air trapped in the windbox section. The inlet valve SV1 is installed on a pipeline connecting the rotameters to the windbox. The outlet valve SV2 is installed on a pipeline connecting the vent line to the bottom of the windbox. Such a system of solenoid valves is used during bed collapse experiments, and it is operated remotely from outside the room hosting the fluidized bed. The two valves have been synchronised to guarantee a simultaneous operation: when the fluidizing gas is shut off by closing valve SV1, SV2 is opened allowing trapped gas in the windbox to be vented. The double venting allows to keep the pressure at the bed bottom at low levels and should limit the gas dynamic effects of the system deaeration.

\subsection{Fundamental fluidization and bed collapse tests}

The minimum fluidization velocity, namely $u_{m f}$, is obtained from the diagrams of the pressure drop profile across the bed over the fluidizing gas velocity, $\mathrm{u}$. The pressure drop profiles are determined by firstly increasing the gas flow rate until the bed is entirely fluidized and then by decreasing the flow rate until the bed is completely settled down: the so-called "fluidization" and "defluidization" curves are then plotted. The experimental minimum fluidization velocity is determined from the intersection of the horizontal fully fluidized bed line and the inclined packed bed line, obtained when decreasing the gas flow rate. Measurements were repeated at least three times in order to verify the reproducibility and the consistency of the outcomes. 
The experimental pressure drop profile represents a powerful tool to discriminate between powders in terms of cohesiveness and flowability. For systems that are easy to fluidize, and which are free from any dominant effect of interparticle forces, the experimental pressure drop at minimum fluidization conditions $\left(\Delta \mathrm{P}_{\mathrm{m}}\right)$ should be equal to the predicted one, $\Delta \mathrm{P}_{\mathrm{c}}$. The latter is calculated according to Eqn (1), where $\mathrm{M}$ is the bed material weight, $\mathrm{g}$ is the gravitational acceleration and XSA is the cross-section area occupied by the material.

$$
\Delta \mathrm{P}_{\mathrm{c}}=\frac{\mathrm{M} \mathrm{g}}{\mathrm{XSA}}
$$

170

Bed expansion profiles are obtained using the X-rays imaging technique that will be described in the following section. The bed height $\mathrm{H}$ is recorded for both fluidization and defluidization stages and plots of $\mathrm{H}$ versus $\mathrm{u}$ are therefore produced for increasing and decreasing gas velocities. From each bed height, the corresponding bed voidage $\varepsilon$ is evaluated considering the particle density $\rho_{\mathrm{p}}$ and the reactor XSA by means of Eqn. (2):

$$
\varepsilon=1-\frac{M}{\mathrm{XSA} \rho_{\mathrm{p}} \mathrm{H}}
$$

In addition, voidage is also calculated from the optical computer-aided analysis of X-ray frames and by following the methodology reported later.

In the present work, the bed collapse tests are run using the system of two solenoid valves (dual-drainage method). When the solenoid valves operate simultaneously, the fluidizing gas trapped in the windbox section is vented out as the gas supply to the bed is cut off. This method ensures measurements of correct values for the dense phase voidage and velocity, as highlighted by Park et al. [48]. Moreover, by using the dual-drainage configuration, the measured parameters do not need any correction due to gas leakage from the windbox, as suggested by some researchers for the single-drainage method $[43,49]$.

When the fluidizing gas is suddenly shut off, the bed material exhibits different collapse profiles depending on the powder properties. Figure 2 reports typical collapse profiles for a gas-solid system with different Geldart group powders, in which three main stages can be observed. The main collapse parameters are then determined and they represent a very helpful tool for the quantification of the capability of the powder to retain the aeration gas and on the existance of other forces opposing to the bed settling.

For type A powders, in the first stage a rapid initial collapse occurs when the bubbles leave the bed (bubble escape stage, $t_{0}<t<t_{b}$ ). An intermediate stage follows, where the dense phase collapses linearly with time until the bed approaches the height at incipient 
193 fluidization (hindered sedimentation stage, $\mathrm{t}_{\mathrm{b}}<\mathrm{t}<\mathrm{t}_{\mathrm{c}}$ ) and the final consolidation of the solid materials is then observed (solid consolidation stage, $\mathrm{t}_{\mathrm{c}}<\mathrm{t}<\mathrm{t}_{\mathrm{s}}$ ).

For Group B and D powders, which show aggregative fluidization for gas velocities above $\mathrm{u}_{\mathrm{mf}}$, the bed collapse curve shows a sharp sedimentation stage as the particles reach the final 197 static bed height as soon as the bubbles are expelled. For these systems, in which $\mathrm{u}_{\mathrm{mb}} / \mathrm{u}_{\mathrm{mf}}=1$, 198 the dense phase may be not expanded at all and, therefore, the consolidation stage may not appear. As a consequence, their collapse rate is much faster than for Group A materials. In these cases, the collapse parameters of major interest are the overall collapse rate $U_{c}$, the standardised collapse time SCT, the overall bed expansion ratio BER and the standardised collapse time of the consolidation stage SCTC [50]. They can be defined as follow:

$$
\begin{gathered}
\mathrm{U}_{\mathrm{c}}=\frac{\mathrm{H}_{0}-\mathrm{H}_{\mathrm{s}}}{\mathrm{t}_{\mathrm{s}}-\mathrm{t}_{0}} \\
\mathrm{BER}=\frac{\mathrm{H}_{0}-\mathrm{H}_{\mathrm{s}}}{\mathrm{H}_{\mathrm{s}}} \times 100 \\
\mathrm{SCT}=\frac{\mathrm{BER}}{\mathrm{U}_{\mathrm{c}}}=\frac{\mathrm{t}_{\mathrm{s}}-\mathrm{t}_{0}}{\mathrm{H}_{\mathrm{s}}} \times 100 \\
\mathrm{SCTC}=\frac{\mathrm{t}_{\mathrm{s}}-\mathrm{t}_{\mathrm{c}}}{\mathrm{H}_{\mathrm{s}}} \times 100
\end{gathered}
$$

203

where $t_{0}$ is the time when the gas supply to the fully bubbling bed is cut off, $t_{c}$ is the time at which the solid consolidation stage begins and $t_{s}$ is the time when the collapse is complete and the bed is completely settled. $\mathrm{H}_{\mathrm{s}}$ is the height of the settled bed, whereas $\mathrm{H}_{0}$ is the value of the bed height at time $t_{0}$.

$\mathrm{U}_{\mathrm{c}}$ is a useful parameter for the measurement of how quickly the bed loses its interstitial aeration gas, whereas BER indicates the maximum expansion to which it is subject.

SCT, which was introduced for the first time in 1985 by Geldart and Wong [26], takes into account that the time required for the powder to settle and it is normalised with respect to the height of the settled bed. Since a significant part of the settling time is taken by the final consolidation, then it accounts for possible changes in the packing process of the settling bed due to changes in the IPFs. To better highlight the effect of the final consolidation stage, SCTC accounts only for the time required for the powder to settle during this stage. Therefore, both SCT and SCTC are good indicators for the detection of changes happening in the bed when changing operative conditions, e.g. temperature, initial gas velocity and PSD of the powder. It can be argued, however, that while $\mathrm{U}_{\mathrm{c}}$ is dominated by the system fluid dynamics, mainly controlling the initial part of the settling process, both SCT and SCTC, the 
latter more than the former, could be more affected by the presence of interparticle forces during the final stages in which particles are closer to each other.

Group C materials display a different collapse curve for either A or B and D powders. There is not a hindered sedimentation stage, but the only consolidation. Geldart and coworkers reported that Group C bed expansion is caused by the presence of cavities and cracks [26,51]. They observed that when the gas is switched off, the largest cracks close up rapidly and further collapse proceeds more slowly, and then the rate of collapse is controlled by the rate at which gas can escape from vertical channels. Besides, they reported that the bed height decreases exponentially with time.

\section{$2.3 X$-ray technique and image analysis}

The X-ray facility is described in [52,53] and it has been widely used for both academic and industrial works to assess the flow phenomena and fluid-particle interactions in dense multiphase systems, to study the bubble dynamics, and to investigate how the operative conditions influence the reactor performance, efficiency and scale-up.

The analysis of the X-ray images provides data that allows quantifying the bed height, the average fluid-bed voidage and the voidage distribution around bubbles, along with expansion and de-aeration profiles.

The high power pulsed X-ray generation facility has been specially designed by Genvolt Ltd., Bridgnorth (UK) and it is capable of providing high-energy cone-shaped pulsed X-ray beams down to $200 \mu \mathrm{s}$ width with an intensity of up to $450 \mathrm{~mA}$ at a voltage variable from $50 \mathrm{kV}$ to $150 \mathrm{kV}$. The $\mathrm{X}$-ray equipment is housed in a radiation-proof room which contains the X-ray source, a $30 \mathrm{~cm}$ image intensifier and a 1024x1024 pixels high-speed charge-coupled device (CCD) camera, mounted on a twin column ceiling suspension unit (see the schematic shown in Figure 3). The system enables to record images with a frequency of up to 72 frames per second (fps) and to capture details with high resolution.

The images captured by the video camera are displayed and stored on a computer using a custom version of the SPS iX-Control software. The software allows the acquisition, the display and the general handling of the frames, as well as the post-processing of the images and their play back up to $72 \mathrm{fps}$ in either real-time or frame by frame. It comes with an extensive set of analysis tools that also allows the off-line data analysis and measurements.

Furthermore, different algorithms for image analysis were developed and implemented in MATLAB. In particular, the collected raw images need to be post-processed in order to be able 
to perform any quantitative hydrodynamic analysis. Among all, the main factors that need to be considered are:

- Pincushion distortion. Due to the intrinsic curvature of the X-ray image intensifier and to the diverging conical shape of the X-ray beam (as shown in Figure 4) that introduce a non-linear magnification across the image. The image magnification increases with the distance from the optical axis. The visible effect is that lines that do not pass through the centre of the image are bowed inwards, towards its centre.

- Penumbra formation at the edge of the image. Due to the limited size of the focal spot, that is defined as the area of the anode on which electrons impinge. The smaller is the focal spot, the smaller will be the penumbra (and then the better will be the image resolution). However, it is essential to note that there is a trade-off between obtaining a small focal spot and the X-ray power, since concentrating a high power beam into a small area may lead to the anode melting.

Such factors can be manipulated by acting on object-to-intensifier distance (OID) and sourceto-intensifier distance (SID), see Figure 4. In particular, the pincushion distortion can be reduced by decreasing OID and increasing SID, as well as the size of the penumbra can be reduced by increasing SID.

The choice of the values of current and voltage employed in this specific analysis was based on visual inspection of the images for fluidized beds operating at different superficial gas velocities: $140 \mathrm{kV}$ voltage and $300 \mathrm{~mA}$ current.

To correct the image pincushion distortion, a global correction method applying a barrel distortion with an appropriate distortion parameter has been employed to every single image [54,55]. The script used is available online at the MathWorks authorised "File Exchange" portal [56] and it required the knowledge of a distortion parameter that depends on the specific source-to-intensifier distance and object-to-intensifier distance. Considering the geometry of the system, a perforated plate with holes of $2 \mathrm{~mm}$ diameter arranged on a $10 \mathrm{~mm}$ square pitch was used as a system to calibrate and get the pincushion distortion parameter [57].

Source-to-intensifier and object-to-intensifier distances were also chosen (SID $=80 \mathrm{~cm}$, OID $=15 \mathrm{~cm}$ ) in order to optimise the quality/intensity of the resulting images by limiting the effects of pincushion distortion and penumbra formation.

The basic procedure adopted for the images analysis is reported in Figure 5, where two Xray raw images of a reactor filled with natural rutile powder are used as examples: one for the 
settled bed and one for a well-fluidized bed. Examples of pincushion correction are also shown, with a grid highlighting the correction effects. The settled bed images are usually used to calibrate the distances. To this end, a square lead marker $(1 \mathrm{x} 1 \mathrm{~cm})$ has been placed to a known height and then used as reference by determining the settled bed height. A region of interest (ROI) is then accurately selected in order to include all the parts of the system needed for the subsequent analysis.

Specific scripts for quantitative analysis of bed height, average fluid-bed voidage and voidage distribution, as well as of the frames from bed collapse tests, have been developed by using different built-in MATLAB functions. An open-access Java package, called MIJ [58], was also used in order to link MATLAB potentialities with more advanced imaging software, namely ImageJ/Fiji [59].

Figure 6 reports examples of images analysis starting from the selected ROI. For the bed height calculation, each grey-level frame is firstly reduced to a binary image by using the MATLAB / Mis inbuilt feature based on Otsu's method [60,61]. Such a feature allows performing adaptive clustering-based image thresholding automatically. The binary images are then segmented in order to distinguish the interface between particles bed and freeboard easily.

301 With particular regard to the bed voidage evaluation, the procedure extendedly reported by Yates and co-workers $[52,62-66]$, that is based on the Beer-Lambert relationship between the attenuation of the X-ray beam and the resulting image intensity, was used.

\section{RESULTS AND DISCUSSION}

\subsection{Pressure drop profiles}

The minimum fluidization velocity was measured at ambient and high temperature (500 ${ }^{\circ} \mathrm{C}$ ) for both rutile powders. In order to guarantee a good mixing of the particles, the bed material was fluidized in a bubbling regime for around 20 minutes before making any measurement.

The pressure drops profiles in Figure 7 are plotted for each sample at the different operative temperatures as the $\Delta \mathrm{P}_{\mathrm{m}} / \Delta \mathrm{P}_{\mathrm{c}}$ ratio and the minimum fluidization velocities obtained, along with the related voidage values $\left(\varepsilon_{\mathrm{mf}}\right)$, are reported in the same figure. $\mathrm{u}_{\mathrm{mf}}$ values show a decreasing trend with increasing temperature for both materials, in agreement with findings in the literature $[14,15]$, mostly linked to the increase of the gas viscosity with 
temperature. The initial settled bed heights $\left(\mathrm{H}_{\mathrm{s}}\right)$ and the related voidage $\left(\varepsilon_{\mathrm{s}}\right)$, calculated from

316 Eqn. (2), are reported as well. The latter was not affected by the temperature in a significant

317 way: this was in disagreement with the findings reported by Botterill et al. [6] and Raso et al.

318 [67] regarding the increases with the temperature of voidage of the settled bed for Group A 319 and B materials.

\subsection{Bed Expansion and Bed Voidage}

The bed material was at first vigorously fluidized to allow proper mixing of the particles, and then the gas flow rate was slowly decreased until the bed settled. The expansion profiles were obtained by slowly increasing the gas velocity at first and by slowly decreasing it afterwards. Recordings of the bed height at various gas velocities were performed through the $\mathrm{X}$-ray facility. At each gas velocity, the bed was allowed to stabilise before recording the Xray images.

Bed expansion and bed voidage profiles obtained at ambient and high temperature (500 ${ }^{\circ} \mathrm{C}$ ) are reported in Figure 8 in terms of deviation from the settled bed height $\left(\mathrm{H}_{\mathrm{s}}\right)$. The profiles obtained for the two materials showed similar characteristics: the expansion is significantly lower at ambient conditions, as well as the deviation from the fluidization to the defluidization stage is less evident.

Differently from what reported by Lettieri [39] and Bruni [68] in similar investigations on Geldart A type powder, the bed expansion profiles do not level off to a specific height value.

334 This suggests that the powders used for this study easily reach conditions of slugging or turbulent regime, in line with the characteristic of sand-like Group B materials.

The bed voidage was also calculated from the optical computer-aided analysis of the X-ray frames according to the methodology presented earlier. The snapshots of the fluidized beds at different gas velocity for SR and NR samples at both ambient and high temperatures are reported in Figure 9 and Figure 10. Each column in the images is representative of the average fluidized conditions of the bed at the referred gas velocity. $72 \mathrm{X}$-ray frames (i.e. 2 seconds of recording) were used for every single snapshot. The images resolution of the frames obtained is 67 pixels $/ \mathrm{cm}$.

It is essential to point out that, due to the limited size of the window left between the ceramic heaters that allows to visualize only half of the bed width, the voidage distribution in the $\mathrm{x}$-direction has been assumed constant and only variations in the y-direction have been reported. This approach allows the analysis of the vertical bed voidage distribution around the 
347 bed axis for the different fluidization regimes, from settled conditions to a fully fluidised bed.

348 As already reported, it can also be helpful to investigate possible dead zones in the reactor

349 and the bubble distribution within the bed. However, the physical characteristics of the

350 particles (high density) caused a significant attenuation of the X-ray beam inside the powder

351 bed, reducing the contrast of the image produced. This prevented a more detailed analysis of

352 the structure of the bed, e.g. visualising the formation and the size of the bubbles. For these

353 reasons, the X-ray parameters have been set to enhance the quality of the images around the

354 boundary between the particles bed and the freeboard. From the figures, it can be seen how

355 the voidage in the bed/freeboard boundary region matches with the average values reported in

356 Figure 8.

\subsection{Bed Collapse Tests}

\subsubsection{Initial gas velocity choice}

The influence of the initial fluidizing velocity $\left(\mathrm{u}_{\mathrm{i}}\right)$ on the bed collapse profiles has been investigated for both the operating temperatures. For each sample, different initial gas velocities were used. Such values were determined by considering different values of fluidization index (FI). Such an index is defined as the ratio of the fluidizing gas velocity to the minimum fluidization velocity:

$$
\mathrm{FI}=\frac{\mathrm{u}_{\mathrm{i}}}{\mathrm{u}_{\mathrm{mf}}}
$$

364 FI has been varied between 1.25 and 4.5. In order to compare the collapse parameters

365 obtained for the various samples with each other, the same values of FI were employed in this work. This allows us to operate in similar fluidization regimes and then to produce meaningful and comparable results.

Figure 11 shows the bed collapse profiles of the SR sample obtained at ambient and high temperature for different initial fluidizing gas velocities reported in Table 2 . In the figures, the bed heights are plotted against the operating time in seconds. The negative values of time indicate periods before the fluidizing gas is suddenly shut off.

It can be qualitatively observed that the bed collapse parameters are affected by the initial gas velocity: apart from the obvious initial height value, also the rate of the sedimentation stage increased with increasing gas velocity.

The experimental data were fitted by means of the following mathematical relationship between bed height and time: 


$$
\mathrm{H}=\frac{\mathrm{H}_{0}-\mathrm{H}_{\mathrm{s}}}{1+\mathrm{e}^{\frac{\mathrm{t}-\mathrm{t}_{\mathrm{i}}}{\tau}}}+\mathrm{H}_{\mathrm{s}}
$$

377

378

379

380

381

382

383

384

385

386

387

388

389

390

391

392

393

394

395

396

397

398

399

400

401

402

403

404

405

406

407

where $\mathrm{H}_{0}$ and $\mathrm{H}_{\mathrm{s}}$ are the initial and the settled bed height respectively, $\mathrm{t}_{\mathrm{i}}$ is the time at which the bed is halfway to the settled/consolidated state (from a mathematical perspective it is the inflexion point of the function) and $\tau$ is a time constant. More details about the fitting analysis will be discussed in the next section.

The same technique was also used on NR samples at both ambient and high temperature. The results were very similar to the ones obtained for the SR samples, and they are plotted in Figure 12.

\subsubsection{Bed collapse test parameters and discussion}

The output parameters from the non-linear fitting of the experimental data through Eqn. (8) are reported in Table 3 for the two investigated materials at different initial gas velocities and operating temperatures. Information on the quality of the fitting test is also reported in terms of descriptive statistics, such as $\mathrm{R}^{2}$ coefficient and residual sum of squares (RSS). According to the findings, i.e. values of $\mathrm{R}^{2}$ close to 1 and low values of RRS, the chosen model give an accurate fitting of the experimental data.

The overall collapse rate $\left(\mathrm{U}_{\mathrm{c}}\right)$, the bed expansion ratio (BER) and the standardised collapse times (SCT and SCTC) were determined from the bed collapse profiles according to what reported in the previous section. They are summarised in Table 4.

The trends of the three parameters at both ambient and high temperature are plotted in Figure 13 for the SR sample. It can be observed that in all the cases, $U_{c}$ and BER increase with increasing the initial gas velocity, but with some differences between ambient and high temperature. The overall collapse rate $\left(U_{c}\right)$ does not seem to be strongly affected by the operating temperature for low initial gas velocities (low decreases have been observed in these cases), whereas it decreases by an average $45 \%$ for the higher gas velocities. Even if the trend of $U_{c}$ is qualitatively in agreement with the modelling correlation suggested by Abrahamsen and Geldart [43] for the dense phase collapse rate, which predicts a slower collapse rate as temperature rises, the change of $U_{c}$ is much smaller than expected in the assumption that the bed settling dynamics would be affected by viscous drag on the particles. In fact, between 25 and $500^{\circ} \mathrm{C}$, such assumption would imply an almost twofold decrease of $\mathrm{U}_{\mathrm{c}}$ as it could be predicted by the twofold increase of the gas viscosity from 1.85 to $3.5610^{-5}$ $\mathrm{Pa} \cdot \mathrm{s}$. Therefore, the limited change of $\mathrm{U}_{\mathrm{c}}$ with temperature can be taken as a proof that, for the systems tested, the defluidization procedure adopted, which allows the contemporary 
escape of air from the bed top and the bed bottom, is able to produce a defluidization experiment that is mostly affected by interparticle forces rather than by the system fluid dynamics. Similarly to $\mathrm{U}_{\mathrm{c}}$, the bed expansion ratio (BER) does not show significant changes with the operating temperature for all the initial gas velocities investigated.

Similar trends for $\mathrm{U}_{\mathrm{c}}$ and BER parameters are observed for the NR samples for both the initial gas velocity and the operating temperature, as reported in Figure 14.

The trends observed for the SCT and SCTC are instead very interesting as, for both the materials tested, they significantly increase with increasing temperature for low initial gas velocities, whereas the deviation attenuates for higher velocities. This means that an increase in temperature increases the bed settling time when the fluidization gas velocity is less than $2 \mathrm{x} \mathrm{u}_{\mathrm{mf}}$. Therefore, unlike $\mathrm{U}_{\mathrm{c}}$ and BER, the SCT showed to be more sensitive to changes in operating conditions. This behaviour is coherent with the interpretation that only the bed consolidation stage is affected by the temperature and that this stage is more significant for tests in which the initial part of the settling experiment, the one not affected by interparticle forces, is limited as it happens in the experiments carried out at conditions close to the incipient fluidization.

Furthermore, it can be observed that the time constant $\tau$ from fitting analysis reported in Table 3 is slightly affected by the initial fluidization conditions, suggesting that it might be a specific property of the powder, although it seems to be temperature-dependent.

In order to support the physical interpretation of the collapse tests, as well as to better understand the role played by the IPFs during the bed collapses, the dimensionless Bond number (Bo) is introduced. Such a number is usually used in fluid dynamics for measuring the importance of the interparticle forces over the gravitational forces. According to the literature $[69,70]$ the granular Bond number for packed beds (Bo) is defined as the ratio of interparticle van der Waals force $F_{v d W}$ to the particle weight $F_{g}$ :

$$
\mathrm{Bo}=\frac{\mathrm{F}_{\mathrm{vdW}}}{\mathrm{F}_{\mathrm{g}}}
$$

The Bond number has been shown to correlate with several bulk-scale powders properties such as bulk density [71,72], flow function coefficient [73] and fluidization performance $[73,74]$.

The particle weight $\mathrm{F}_{\mathrm{g}}$ can be evaluated according to the following equation:

$$
F_{g}=\frac{\pi}{6} \rho_{p} g_{p}^{3}
$$


437 Eqn. (11) is used to estimate the adhesion forces $F_{v d W}$ between particles of diameter $d_{s v}$ 438 according to the procedure discussed in [46] for shear tests:

$$
\mathrm{F}_{\mathrm{vdW}}=\sigma_{0} \mathrm{~d}_{\mathrm{sv}}^{2} \frac{\varepsilon_{\mathrm{c}}}{1-\varepsilon_{\mathrm{c}}}
$$

439 where $\sigma_{0}$ is the isostatic tensile strength of the unconsolidated powder, i.e. it well represents 440 the consolidation state typical of a fluidized bed. $\varepsilon_{\mathrm{c}}$ is defined as the initial porosity of the 441 loose powder packing [75] and, therefore, the voidage of the bed at the time $t_{c}$ has been 442 considered. The values of $\sigma_{0}$ and $\varepsilon_{\mathrm{c}}$ used are reported in Table 3.The procedure used for the 443 determination of the parameter $t_{c}$ is schematically shown in Figure 15. It has been determined 444 as the time at which the collapse curve moves away from the linear profile of the hindered sedimentation stage. In particular, a deviation threshold of $10 \%$ from the linear slope of the curve has been applied for the identification of such a point. Repeated experiments at the same conditions suggest a standard deviation of the results below the $15 \%$.

Figure 16 reports the comparison of the SCT and SCTC values to the Bo number. It can be observed that the greater the Bo number, the higher is the value of SCTC. More importantly, the ratio SCTC/SCT, which is representative of the relative weight of the time taken consolidation stage over the whole collapse/deaeration time, is higher ( 25\%) when the Bo number is $>1$ than in the case for Bo $<1(\sim 10 \%)$. This means that for the systems operating at high temperature the overall collapse process is slowed down due to the domination of the IPFs over the gravitational forces.

It is possible to look at the bed settling curves represented in Figure 15 using the concepts of the Wallis theory [76] on continuity waves applied to the settling of particulate. According to this theory, the lack of a cusp between the descending part of the curve, representing the descending bed surface, and the horizontal line, corresponding to the settled bed, is an indication of the presence of interparticle forces, which hinder the bed compression and avoid

460 the formation of a sharp compression shock wave travelling upwards within the bed, during 461 the bed collapse. The presence of interparticle forces, instead, determine a bundle of 462 concentration waves that propagate upwards from the distributor with different speeds according to the local concentration, as shown in the qualitative representation depicted in the insert of the upper central pane (SR25, FI=3) of Figure 15. In particular, the fastest concentration wave is the one corresponding to the first emerging on the bed surface at $t_{c}$ and the slowest is the last emerging on the bed surface at $t_{s}$. The trajectories of these waves are empirically represented with hyphenated lines corresponding to the changing heights within the bed at equal bed voidage. These lines qualitatively describe the bed concentration profiles 
during the bed settling process in the solid consolidation stage. It can be observed, from

470 similar lines represented in the other panes of Figure 15 reporting quantitatively the bed settling process for different experimental conditions (temperature and fluidization index), how the sedimentation of the particles is slowed down at the higher operating temperature $\left(500^{\circ} \mathrm{C}\right)$ as it appears from the more extended areas covered by the lines (only partially shown) representing the concentration waves.

475

476

477

478

479

480

481

482

483

484

485

486

487

488

489

490

491

492

493

494

495

496

497

498

499

500

\section{CONCLUSIONS}

This paper reported on the experimental results obtained from fluidization tests performed on two types of rutile powders, namely synthetic and natural. The findings for each of the materials investigated laid the basis for a better understanding of the behaviour of the powders when operated in the fluidized bed reactor, as well as their performance when mixed with other components in the industrial plant operations. The results from fluidization tests were discussed in order to link the observed changes in the powders' fluidization behaviour with their powder flow properties.

The powders showed a typical Group B behaviour: aggregative fluidization (bubbles form once the gas velocity exceeds the minimum fluidization velocity), relatively small bed expansion and bed collapse curve showing a sharp sedimentation stage. The bed collapse test was found to highlight the effects that can be related to the change of interparticle forces with temperature. The collapsing parameters were related to the powder flow behaviour of the materials examined.

For all the materials tested, the overall collapse rate $\left(U_{c}\right)$ and the bed expansion ratio (BER) increased with increasing the initial gas velocity, but with some differences between ambient and high temperature. $U_{c}$ does not seem to be strongly affected by the operating temperature for low initial gas velocities, whereas it decreases by $45 \%$ on average for the higher gas velocities. Instead, BER does not show significant changes with the operating temperature for all the initial gas velocities investigated.

On the other hand, the standardised collapse times (SCT and SCTC) showed to be very sensitive to the changes in operating conditions: initial gas velocity and related bed expansion in particular. They increased significantly with increasing temperature for low initial gas velocities, while such a deviation decreased at higher velocities. This suggested that higher temperature improves the ability of the bed to resist compression in the final part of the settling bed experiment and that this effect is more significant in experiments starting from a 
501 limited bed expansion, as it happens when the fluidization gas velocity is less than $2 \mathrm{x}_{\mathrm{mf}}$. 502 This behaviour was explained as a function of the role played by the IPFs on the fluidization 503 regimes. These can be quantified by deriving interparticle force from powder flow tests and 504 using these values to estimate the dimensionless Bond number, which is commonly used in 505 fluid dynamics for measuring the importance of the interparticle forces over the gravitational 506 forces. The analysis showed that the greater such parameter, the slower is the overall bed 507 collapse process and consolidation of the bed due to the increasingly dominant effect of the 508 IPFs over the gravitational forces. 


\section{FIGURES CAPTIONS}

510 Figure 1 - Schematic layout of the fluidization rig

511 Figure 2 - Typical collapse profiles for different Geldart group powders and main stages in the BCT.

512 Figure 3 - Schematic of the X-ray Imaging Technique and the fluid bed system

513 Figure 4-Top view of the X-ray Imaging Technique and the fluid bed system

514 Figure 5 - Examples of basic images analysis procedures

515 Figure 6 - Examples of image processing: bed height and voidage distribution.

516 Figure 7 - Pressure Drop profiles for SR and NR samples at ambient and high temperature

517 Figure $8-$ Bed expansion and bed voidage profiles for SR and NR samples at $25^{\circ} \mathrm{C}$ (SR25 and NR25)

518 and $500^{\circ} \mathrm{C}(\mathrm{SR} 500$ and NR500)

519 Figure 9 - Snapshots of the fluidized bed at different gas velocity for SR samples at ambient (SR25) 520 and high temperature (SR500). Colorbar: bed voidage.

521 Figure 10 - Snapshots of the fluidized bed at different gas velocity for NR samples at ambient (NR25)

522 and high temperature (NR500). Colorbar: bed voidage

523 Figure $11-$ Collapse profiles at $25^{\circ} \mathrm{C}$ and $500{ }^{\circ} \mathrm{C}$ for SR sample at different fluidization indexes

524 Figure 12 - Collapse profiles at $25{ }^{\circ} \mathrm{C}$ and $500{ }^{\circ} \mathrm{C}$ for NR sample at different fluidization indexes

525 Figure 13 - Effect of temperature on the collapse parameters for SR sample

526 Figure 14 - Effect of temperature on the collapse parameters for NR sample

527 Figure 15 - Examples of bed collapse profile and sedimentation continuity waves during experiments

528 Figure 16 - Comparison of SCTC and SCTC/SCT values to the variation of Bo numbers

\section{TABLES CAPTIONS}

531 Table 1 - Main physical properties of the investigated materials

532 Table 2 - Initial gas velocity for the BCT

533 Table 3 - Eqn. (8) fittings parameters for all the samples

534 Table 4 - Collapse parameters

535

536 


\section{REFERENCES}

538 [1] Kunii, D., Levenspiel, O., Fluidization engineering, Elsevier, 1991.

539 [2] B. Jazayeri, Applications for Chemical Production and processing, in: Handb. Fluid. Fluid-Particle Syst., 2003: pp. 421-444.

541 [3] F. Winter, B. Schratzer, Applications of fluidized bed technology in processes other than combustion and gasification, in: Fluid. Bed Technol. Near-Zero Emiss. Combust. Gasif., Elsevier, 2013: pp. 1005-1033. doi:10.1533/9780857098801.5.1005.

[4] J.G. Yates, P. Lettieri, Fluidized-Bed Reactors: Processes and Operating Conditions, Springer International Publishing, Cham, 2016. doi:10.1007/978-3-319-39593-7.

[5] D. Macrì, S. Sutcliffe, P. Lettieri, Fluidized bed sintering in TiO2 and coke systems, Chem. Eng. J. 381 (2020) 122711. doi:10.1016/j.cej.2019.122711.

[6] J.S.M. Botterill, Y. Teoman, K.R. Yüregir, The effect of operating temperature on the velocity of minimum fluidization, bed voidage and general behaviour, Powder Technol. 31 (1982) 101-110.

[7] A. Lucas, J. Arnaldos, J. Casal, L. Puigjaner, High temperature incipient fluidization in mono and polydisperse systems, Chem. Eng. Commun. 41 (1986) 121-132. doi:10.1080/00986448608911715.

[8] N.S. Grewal, A. Gupta, Total and gas convective heat transfer from a vertical tube to a mixed particle gas—solid fluidized bed, Powder Technol. 57 (1989) 27-38. doi:10.1016/0032-5910(89)80101-9.

[9] D. Geldart, Estimation of basic particle properties for use in fluid - particle process calculations, Powder Technol. 60 (1990) 1-13. doi:10.1016/0032-5910(90)80099-K.

[10] J. Fletcher, M.M. Deo, F. Hanson, Re-examination of minimum fluidization velocity correlations applied to Group B sands and coked sands, Powder Technol. 69 (1992) $147-155$.

[11] P. Lettieri, D. Newton, J.G. Yates, Homogeneous bed expansion of FCC catalysts, influence of temperature on the parameters of the Richardson-Zaki equation, Powder Technol. 123 (2002) 221-231. doi:10.1016/S0032-5910(01)00463-6.

[12] R. Coltters, a. L. Rivas, Minimum fluidation velocity correlations in particulate 
systems, Powder Technol. 147 (2004) 34-48. doi:10.1016/j.powtec.2004.06.013.

567

568

569

570

571

572

573

574

575

576

577

578

579

580

581

582

583

584

585

586

587

588

589

590

591

592

593

594

[13] T.M. Knowlton, Pressure and temperature effects in fluid-particle systems, in: Fluid. VII, Engineering Foundation: New York, 1992: pp. 27-46.

[14] J.G. Yates, Effects of temperature and pressure on gas-solid fluidization, Chem. Eng. Sci. 51 (1996) 168-205.

[15] P. Lettieri, D. Macrì, Effect of Process Conditions on Fluidization, KONA Powder Part. J. 2016 (2016) 1-24. doi:/10.14356/kona.2016017.

[16] J.P.K. Seville, R. Clift, The effect of thin liquid layers on fluidization characteristics, Powder Technol. 37 (1984) 117-129.

[17] V.G. Reiling, The effects of ultrafine particles on powder cohesion and fluidization. Ph.D. Thesis, Case Westner Reserve University, 1992.

[18] D. Newton, G. Smith, N. Hird, Comments on experimental data on the suitability of assigning a viscosity to the fluidized bed dense phase, in: Unpubl. Pap. Present. Fifth Int. Conf. Fluid Part. Interact., 1999.

[19] T. Kai, M. Murakami, K. Yamasaki, T. Takahashi, Relationship between apparent bed viscosity and fluidization quality in a fluidized bed with fine particles, J. Chem. Eng. Japan. 24 (1991) 494-500.

[20] H.O. Kono, S. Narasimhan, L.M. Richman, T. Ohtake, Flow properties of homogeneously aerated, expanded emulsion phase of fine powders (quasi-solid emulsion phase viscosity), Powder Technol. 122 (2002) 168-176. doi:10.1016/S00325910(01)00413-2.

[21] M.A.S. Quintanilla, A. Castellanos, J.M. Valverde, Correlation between bulk stresses and interparticle contact forces in fine powders., Phys. Rev. E. Stat. Nonlin. Soft Matter Phys. 64 (2001) 031301. doi:10.1103/PhysRevE.64.031301.

[22] A. Castellanos, J.M. Valverde, M.A.S. Quintanilla, Fine cohesive powders in rotating drums: Transition from rigid-plastic flow to gas-fluidized regime, Phys. Rev. E - Stat. Nonlinear, Soft Matter Phys. 65 (2002) 1-7. doi:10.1103/PhysRevE.65.061301.

[23] G. Bruni, A. Colafigli, P. Lettieri, T. Elson, Torque Measurements in Aerated Powders Using a Mechanically Stirred Fluidized Bed Rheometer (msFBR), Chem. Eng. Res. 
596

597

598

599

600

601

602

603

604

605

606

607

608

609

610

611

612

613

614

615

616

617

618

619

620

621

622

623

[24] I. Tomasetta, D. Barletta, P. Lettieri, M. Poletto, The measurement of powder flow properties with a mechanically stirred aerated bed, Chem. Eng. Sci. 69 (2012) 373381. doi:10.1016/j.ces.2011.10.056.

[25] H.M. Sutton, R.A. Richmond, Improving the storage conditions of fine powders by aeration, Trans. Inst. Chem. Eng. 51 (1973) 97.

[26] Geldart, D., A.A.C.Y. Wong, D. Geldart, A.A.C.Y. Wong, Fluidization of powders showing degrees of cohesiveness-II. Experiments on rates of de-aeration, Chem. Eng. Sci. 40 (1985) 653-661.

[27] G. Khoe, T. Ip, J.R. Grace, Rheological and fluidization behaviour of powders of different particle size distribution, Powder Technol. 66 (1991) 127-141.

[28] M.J. Lorences, G.S. Patience, F. V Díez, J. Coca, Fines effects on collapsing fluidized beds, Powder Technol. 131 (2003) 234-240. doi:10.1016/S0032-5910(03)00004-4.

[29] G. Bruni, P. Lettieri, D. Newton, J.G. Yates, The influence of fines size distribution on the behaviour of gas fluidized beds at high temperature, Powder Technol. 163 (2006) 88-97. doi:10.1016/j.powtec.2006.01.007.

[30] G.W. Brown, Direct measurement of FCC fluidizability helps spot problems, Oil Gas J. 88 (1990).

[31] K. Rietema, Proceedings of the International Conference on fluidization, in: Proc. Int. Conf. Fluid. Ed. by A. A. H. Drink. Amsterdam, 1967: p. 154.

[32] A.R. Abrahamsen, D. Geldart, Behaviour of gas-fluidized beds of fine powders part I. Homogeneous expansion, Powder Technol. 26 (1980) 35-46. doi:10.1016/0032$5910(80) 85005-4$.

[33] G.F. Barreto, J.G. Yates, P.N. Rowe, The measurement of emulsion phase voidage in gas fluidized beds of fine powders, Chem. Eng. Sci. 38 (1983) 345.

[34] G. Barreto, G. Mazza, J.G. Yates, The significance of bed collapse experiments in the characterization of fluidized beds of fine powders, Chem. Eng. Sci. 43 (1988) 30373047.

[35] B. Formisani, R. Girimonte, L. Mancuso, Analysis of the fluidization process of 
particle beds at high temperature, Chem. Eng. Sci. 53 (1998) 951-961.

625

626

627

628

629

630

631

632

633

634

635

636

637

638

639

640

641

642

643

644

645

646

647

648

649

650

651

652

[36] B. Formisani, R. Girimonte, G. Pataro, The influence of operating temperature on the dense phase properties of bubbling fluidized beds of solids, Powder Technol. 125 (2002) 28-38.

[37] R. Girimonte, B. Formisani, Effects of operating temperature on the bubble phase properties in fluidized beds of FCC particles, Powder Technol. 262 (2014) 14-21. doi:10.1016/j.powtec.2014.04.041.

[38] G. Bruni, P. Lettieri, D. Newton, D. Barletta, An investigation of the effect of the interparticle forces on the fluidization behaviour of fine powders linked with rheological studies, Chem. Eng. Sci. $62 \quad$ (2007) 387-396. doi:10.1016/j.ces.2006.08.059.

[39] P. Lettieri, A study on the influence of temperature on the flow behaviour of solid materials in a gas fluidized bed. Ph.D. Thesis, University College London (1999).

[40] P. Lettieri, J.G. Yates, D. Newton, The influence of interparticle forces on the fluidization behaviour of some industrial materials at high temperature, Powder Technol. 110 (2000) 117-127. doi:10.1016/S0032-5910(99)00274-0.

[41] P. Lettieri, D. Newton, J.G. Yates, High temperature effects on the dense phase properties of gas fluidized beds, Powder Technol. 120 (2001) 34-40. doi:10.1016/S0032-5910(01)00344-8.

[42] D. Geldart, A. Wong, Fluidization of powders showing degrees of cohesiveness-I. Bed expansion, Chem. Eng. Sci. 39 (1984) 1481-1488.

[43] A. Abrahamsen, D. Geldart, Behaviour of gas-fluidized beds of fine powders part II. Voidage of the dense phase in bubbling beds, Powder Technol. 26 (1980) 47-55. http://www.sciencedirect.com/science/article/pii/0032591080850066.

[44] D. Macri, Study of defluidization behaviour of industrial reactive particles, Ph. D. Thesis, University College London (2018). http://discovery.ucl.ac.uk/10064060/.

[45] D. Macrì, M. Poletto, D. Barletta, S. Sutcliffe, P. Lettieri, Analysis of industrial reactive powders flow properties at high temperature, Powder Technol. 316 (2017) 131-138. doi:10.1016/j.powtec.2016.10.064. 
[46] D. Macrì, D. Barletta, P. Lettieri, M. Poletto, Experimental and theoretical analysis of $\mathrm{TiO} 2$ powders flow properties at ambient and high temperatures, Chem. Eng. Sci. 167 (2017) 172-190. doi:10.1016/j.ces.2017.03.057.

[47] D. Geldart, Gas Fluidization Technology, Wiley, 1987.

[48] J.H.J.H.J. Park, J.H.J.H.J. Park, I.S. Chang, S.D. Kim, C.S. Choi, A new bedcollapsing technique for measuring the dense phase properties of gas-fluidized beds, Powder Technol. 66 (1991) 249-257. doi:10.1016/0032-5910(91)80038-K.

[49] M. Kwauk, Fluidization: idealized and bubbleless, with applications, Science Press, 1992.

[50] P. Lettieri, D. Newton, J.G. Yates, Experimental observations of fluidized beds at high temperatures, Eurasian Chem. J. 1 (1999) 9. doi:10.18321/ectj342.

[51] D. Geldart, N. Harnby, A.C.Y. Wong, Fluidization of cohesive powders, Powder Technol. 37 (1984) 25-37. doi:10.1016/0032-5910(84)80003-0.

[52] P. Lettieri, J.G. Yates, New Generation X-ray Imaging for multiphase systems, Fluid. XIV. (2013) 641-648.

[53] L. Panariello, M. Materazzi, R. Solimene, P. Salatino, P. Lettieri, X-ray imaging of horizontal jets in gas fluidised bed nozzles, Chem. Eng. Sci. 164 (2017) 53-62. doi:10.1016/j.ces.2017.01.055.

[54] G. Vass, T. Perlaki, Applying and removing lens distortion in post production, Proc. 2nd Hungarian Conf. Comput. Graph. Geom. (2009) 9-16. http://citeseerx.ist.psu.edu/viewdoc/download?doi=10.1.1.136.3745\&amp;rep=rep1\&a mp;type=pdf.

[55] H. Ojanen, Automatic Correction of Lens Distortion by Using Digital Image Processing, (1999).

[56] J. de Vries, Barrel and pincushion lens distortion correction, Matlab Cent. - File Exch. (2012). https://uk.mathworks.com/matlabcentral/fileexchange/37980-barrel-andpincushion-lens-distortion-correction?s_tid=prof_contriblnk.

[57] S. Tebianian, Comparison of alternative advanced experimental techniques for measurement of hydrodynamic characteristics of gas- fluidized beds, Ph.D. Thesis, 
[58] D. Sage, D. Prodanov, J.-Y. Tinevez, J. Schindelin, MIJ: Making Interoperability Between ImageJ and Matlab Possible, in: ImageJ User Dev. Conf., Luxembourg (2012), pp. 24-26.

686

[59] ImageJ, Miji package, (2016). http://imagej.net/Miji (accessed March 9, 2018).

687

[60] J. Ma, D. Liu, X. Chen, Bubble Behaviors of Large Cohesive Particles in a 2D 688

Fluidized Bed, Ind. Eng. Chem. Res. 55 (2016) 624-634. doi:10.1021/acs.iecr.5b02789.

690

[61] S.U. Lee, S. Yoon Chung, R.H. Park, A comparative performance study of several global thresholding techniques for segmentation, Comput. Vision, Graph. Image

[62] J.G. Yates, D.J. Cheesman, P. Lettieri, D. Newton, X-ray analysis of fluidized beds and other multiphase systems, KONA Powder Part. J. 20 (2002) 133-143. doi:10.14356/kona.2002016.

[63] S. Tebianian, N. Ellis, P. Lettieri, J.R. Grace, X-ray imaging for flow characterization and investigation of invasive probe interference in travelling fluidized bed, Chem. Eng. Res. Des. 104 (2015) 191-202. doi:10.1016/j.cherd.2015.08.006.

[64] J.G. Yates, D.J. Cheesman, B. Engineering, Experimental Observations of Voidage

701

702

703

704

705

706

707

708

709

710 Distribution, Chem. Eng. Sci. 49 (1994) 1885-1895.

[65] J.G. Yates, S.J.R. Simons, Experimental methods in fluidization research, Int. J. Multiph. Flow. 20 (1994) 297-330. doi:10.1016/0301-9322(94)90076-0.

[66] J.G. Yates, D.J. Cheesman, Y.A. Sergeev, Experimental observations of voidage distribution around bubbles in a fluidized bed, Chem. Eng. Sci. 49 (1994) 1885-1895. doi:10.1016/0009-2509(94)80073-1.

[67] G. Raso, M. D'Amore, B. Formisani, P. Lignola, The influence of temperature on the properties of the particulate phase at incipient fluidization, Powder Technol. 72 (1992) 71-76.

[68] G. Bruni, An investigation of the influence of fines size distribution and high temperature on the fluidization behaviour of gas fluidized beds linked with rheological 
studies. Ph.D. Thesis, University College London, 2005.

712

713

714

715

716

717

718

719

720

721

722

723

724

725

726

727

728

729

730

731

732

733

734

735

736

[69] J.M. Valverde, A. Castellanos, P. Mills, M.A.S. Quintanilla, Effect of particle size and interparticle force on the fluidization behavior of gas-fluidized beds., Phys. Rev. E. Stat. Nonlin. Soft Matter Phys. 67 (2003) 051305. doi:10.1103/PhysRevE.67.051305.

[70] S.T. Nase, W.L. Vargas, A.A. Abatan, J.J. McCarthy, Discrete characterization tools for cohesive granular material, Powder Technol. $116 \quad$ (2001) 214-223. doi:10.1016/S0032-5910(00)00398-3.

[71] A.B. Yu, C.L. Feng, R.P. Zou, R.Y. Yang, On the relationship between porosity and interparticle forces, Powder Technol. 130 (2003) 70-76. doi:10.1016/S00325910(02)00228-0.

[72] M. Capece, Z. Huang, D. To, M. Aloia, C. Muchira, R.N. Davé, A.B. Yu, Prediction of porosity from particle scale interactions: Surface modification of fine cohesive powders, Powder Technol. 254 (2014) 103-113. doi:10.1016/j.powtec.2014.01.006.

[73] M. Capece, R. Ho, J. Strong, P. Gao, Prediction of powder flow performance using a multi-component granular Bond number, Powder Technol. 286 (2015) 561-571. doi:10.1016/j.powtec.2015.08.031.

[74] Y. Chen, L. Jallo, M.A.S. Quintanilla, R. Dave, Characterization of particle and bulk level cohesion reduction of surface modified fine aluminum powders, Colloids Surfaces A Physicochem. Eng. Asp. $361 \quad$ (2010) 66-80. doi:10.1016/j.colsurfa.2010.03.015.

[75] J. Tomas, The mechanics of dry, cohesive powders, Powder Handl. Process. 15 (2003) 296-314.

[76] G.B. Wallis, Suspensions of Particles in Fluids, in: One-Dimensional Two-Phase Flow, McGraw-Hill, 1969: pp. 175-242. 
Table 1 - Main physical properties of the investigated materials

\begin{tabular}{lccccccc}
\hline Sample & $\rho_{\mathrm{p}}\left(\mathrm{kg} / \mathrm{m}^{3}\right)$ & $\rho_{\mathrm{b}, 25^{\circ}}\left(\mathrm{kg} / \mathrm{m}^{3}\right)$ & $\mathrm{d}_{16}(\mu \mathrm{m})$ & $\mathrm{d}_{50}(\mu \mathrm{m})$ & $\mathrm{d}_{84}(\mu \mathrm{m})$ & $\mathrm{d}_{\mathrm{sv}}(\mu \mathrm{m})$ & $\mathrm{RDS}=\frac{\mathrm{d}_{84}-\mathrm{d}_{16}}{2 \mathrm{~d}_{50}}(-)$ \\
\hline Synthetic Rutile (SR) & 3200 & 1500 & 122 & 162 & 212 & 145 & 0.28 \\
Natural Rutile (NR) & 4200 & 2320 & 117 & 202 & 379 & 155 & 0.65 \\
\hline
\end{tabular}

Table 2 - Initial gas velocity for the BCT

\begin{tabular}{lcccccccc}
\hline \multirow{2}{*}{ Sample } & $\mathrm{u}_{\mathrm{mf}}(\mathrm{cm} / \mathrm{s})$ & \multicolumn{7}{c}{ FI $(-)$} \\
\cline { 3 - 9 } & & 1.25 & 1.50 & 2.00 & 2.50 & 3.00 & 4.00 & 4.50 \\
\hline SR25 & 2.3 & 2.8 & 3.4 & 4.5 & 5.7 & 6.8 & 9.0 & 10.2 \\
SR500 & 0.6 & 0.8 & 0.9 & 1.3 & 1.6 & 1.9 & 2.5 & 2.8 \\
NR25 & 2.7 & 3.4 & 4.1 & 5.4 & 6.8 & 8.1 & 10.8 & 12.2 \\
NR500 & 0.9 & 1.1 & 1.3 & 1.7 & 2.2 & 2.6 & 3.5 & 3.9 \\
\hline
\end{tabular}

Table 3 - Eqn. (8) fittings parameters for all the samples

\begin{tabular}{|c|c|c|c|c|c|c|c|c|}
\hline \multirow{2}{*}{ Sample } & \multirow{2}{*}{ Parameter } & \multicolumn{7}{|c|}{ FI (-) } \\
\hline & & 1.25 & 1.50 & 2.00 & 2.50 & 3.00 & 4.00 & 4.50 \\
\hline \multirow[t]{2}{*}{$\overline{\text { SR25 }}$} & $\mathrm{H}_{0}, \mathrm{~cm}$ & 25.7 & 26.2 & 26.7 & 27.3 & 27.8 & 28.5 & 28.8 \\
\hline & $\mathrm{H}_{\mathrm{s}}, \mathrm{cm}$ & 25.2 & 25.2 & 25.2 & 25.2 & 25.2 & 25.2 & 25.2 \\
\hline$\varepsilon_{\mathrm{c}}=0.55$ & $\mathrm{t}_{\mathrm{i}}, \mathrm{sec}$ & 0.78 & 0.73 & 0.75 & 0.76 & 0.71 & 0.72 & 0.70 \\
\hline \multirow[t]{3}{*}{$\sigma_{0}=0.9 \mathrm{~Pa}$} & $\tau, \sec$ & 0.15 & 0.12 & 0.15 & 0.12 & 0.14 & 0.17 & 0.16 \\
\hline & $\mathrm{R}^{2}$ & 0.984 & 0.983 & 0.987 & 0.977 & 0.970 & 0.972 & 0.966 \\
\hline & RSS & 0.141 & 0.614 & 1.235 & 4.181 & 8.015 & 12.038 & 17.650 \\
\hline \multirow[t]{2}{*}{ SR500 } & $\mathrm{H}_{0}, \mathrm{~cm}$ & 26.7 & 27.0 & 27.6 & 27.9 & 28.5 & 28.6 & 29.2 \\
\hline & $\mathrm{H}_{\mathrm{s}}, \mathrm{cm}$ & 25.6 & 25.6 & 25.6 & 25.6 & 25.6 & 25.6 & 25.6 \\
\hline$\varepsilon_{\mathrm{c}}=0.56$ & $\mathrm{t}_{\mathrm{i}}, \mathrm{sec}$ & 1.16 & 1.14 & 1.00 & 0.96 & 0.87 & 0.84 & 0.86 \\
\hline \multirow{3}{*}{$\sigma_{0}=21.5 \mathrm{~Pa}$} & $\tau, \sec$ & 0.30 & 0.28 & 0.26 & 0.21 & 0.24 & 0.23 & 0.19 \\
\hline & $\mathrm{R}^{2}$ & 0.998 & 0.991 & 0.983 & 0.986 & 0.977 & 0.977 & 0.959 \\
\hline & RSS & 0.073 & 0.546 & 2.226 & 2.611 & 6.822 & 7.535 & 20.127 \\
\hline \multirow[t]{2}{*}{ NR25 } & $\mathrm{H}_{0}, \mathrm{~cm}$ & 16.0 & 16.2 & 16.9 & 17.4 & 17.7 & 18.3 & 18.8 \\
\hline & $\mathrm{H}_{\mathrm{s}}, \mathrm{cm}$ & 15.5 & 15.5 & 15.5 & 15.5 & 15.5 & 15.5 & 15.5 \\
\hline$\varepsilon_{\mathrm{c}}=0.45$ & $\mathrm{t}_{\mathrm{i}}, \mathrm{sec}$ & 0.58 & 0.58 & 0.60 & 0.61 & 0.64 & 0.60 & 0.56 \\
\hline \multirow[t]{3}{*}{$\sigma_{0}=2.5 \mathrm{~Pa}$} & $\tau, \sec$ & 0.06 & 0.07 & 0.08 & 0.07 & 0.11 & 0.08 & 0.11 \\
\hline & $\mathrm{R}^{2}$ & 0.964 & 0.988 & 0.994 & 0.987 & 0.980 & 0.973 & 0.978 \\
\hline & RSS & 0.334 & 0.246 & 0.556 & 2.127 & 4.251 & 8.721 & 10.389 \\
\hline \multirow[t]{2}{*}{ NR500 } & $\mathrm{H}_{0}, \mathrm{~cm}$ & 17.1 & 17.5 & 18.0 & 18.0 & 18.5 & 19.0 & 19.4 \\
\hline & $\mathrm{H}_{\mathrm{s}}, \mathrm{cm}$ & 16.5 & 16.5 & 16.5 & 16.5 & 16.5 & 16.5 & 16.5 \\
\hline$\varepsilon_{\mathrm{c}}=0.48$ & $\mathrm{t}_{\mathrm{i}}, \mathrm{sec}$ & 0.84 & 0.86 & 0.78 & 0.78 & 0.74 & 0.71 & 0.65 \\
\hline \multirow[t]{3}{*}{$\sigma_{0}=11.2 \mathrm{~Pa}$} & $\tau, \sec$ & 0.18 & 0.18 & 0.16 & 0.16 & 0.12 & 0.12 & 0.09 \\
\hline & $\mathrm{R}^{2}$ & 0.980 & 0.985 & 0.986 & 0.981 & 0.985 & 0.959 & 0.953 \\
\hline & RSS & 0.299 & 0.541 & 1.122 & 2.885 & 2.528 & 10.696 & 16.773 \\
\hline
\end{tabular}


Table 4 - Collapse parameters

\begin{tabular}{llccccccc}
\hline \multirow{3}{*}{ Sample } & & \multicolumn{7}{c}{ FI $(-)$} \\
\cline { 3 - 8 } & & Parameter & & & & \\
\cline { 3 - 8 } SR25 & $\mathrm{U}_{\mathrm{c}}, \mathrm{cm} / \mathrm{s}$ & 0.4 & 0.9 & 1.3 & 1.9 & 2.3 & 2.7 & 3.1 \\
& $\mathrm{BER}, \%$ & 1.9 & 3.8 & 6.2 & 8.3 & 10.4 & 13.3 & 14.3 \\
& $\mathrm{SCT}, \mathrm{s} / \mathrm{cm}$ & 4.9 & 4.3 & 4.8 & 4.4 & 4.5 & 4.9 & 4.6 \\
& $\mathrm{SCTC}, \mathrm{s} / \mathrm{cm}$ & 1.1 & 0.9 & 1.1 & 0.9 & 1.0 & 1.3 & 1.2 \\
SR500 & $\mathrm{U}_{\mathrm{c}}, \mathrm{cm} / \mathrm{s}$ & 0.5 & 0.6 & 1.0 & 1.3 & 1.6 & 1.7 & 2.2 \\
& $\mathrm{BER}, \%$ & 4.2 & 5.4 & 7.6 & 9.0 & 11.2 & 11.6 & 13.8 \\
& $\mathrm{SCT}, \mathrm{s} / \mathrm{cm}$ & 9.1 & 8.8 & 7.8 & 7.0 & 7.0 & 6.8 & 6.3 \\
& $\mathrm{SCTC}, \mathrm{s} / \mathrm{cm}$ & 2.2 & 2.1 & 1.9 & 1.6 & 1.8 & 1.7 & 1.4 \\
NR25 & $\mathrm{U}_{\mathrm{c}}, \mathrm{cm} / \mathrm{s}$ & 0.6 & 0.8 & 1.7 & 2.2 & 2.5 & 3.1 & 3.8 \\
& $\mathrm{BER}, \%$ & 2.9 & 4.4 & 9.3 & 12.5 & 14.5 & 17.8 & 21.5 \\
& $\mathrm{SCT}, \mathrm{s} / \mathrm{cm}$ & 5.1 & 5.4 & 5.6 & 5.6 & 5.9 & 5.7 & 5.6 \\
& $\mathrm{SCTC}, \mathrm{s} / \mathrm{cm}$ & 0.7 & 0.8 & 0.9 & 0.8 & 0.9 & 0.9 & 1.0 \\
NR5000 & $\mathrm{U}_{\mathrm{c}}, \mathrm{cm} / \mathrm{s}$ & 0.4 & 0.6 & 1.0 & 1.0 & 1.7 & 2.1 & 2.6 \\
& $\mathrm{BER}, \%$ & 3.8 & 5.9 & 8.7 & 8.7 & 12.2 & 15.1 & 17.2 \\
& $\mathrm{SCT}, \mathrm{s} / \mathrm{cm}$ & 9.4 & 9.4 & 8.4 & 8.4 & 7.3 & 7.3 & 6.5 \\
& $\mathrm{SCTC}, \mathrm{s} / \mathrm{cm}$ & 2.1 & 2.0 & 1.8 & 1.8 & 1.4 & 1.4 & 1.2 \\
\hline
\end{tabular}




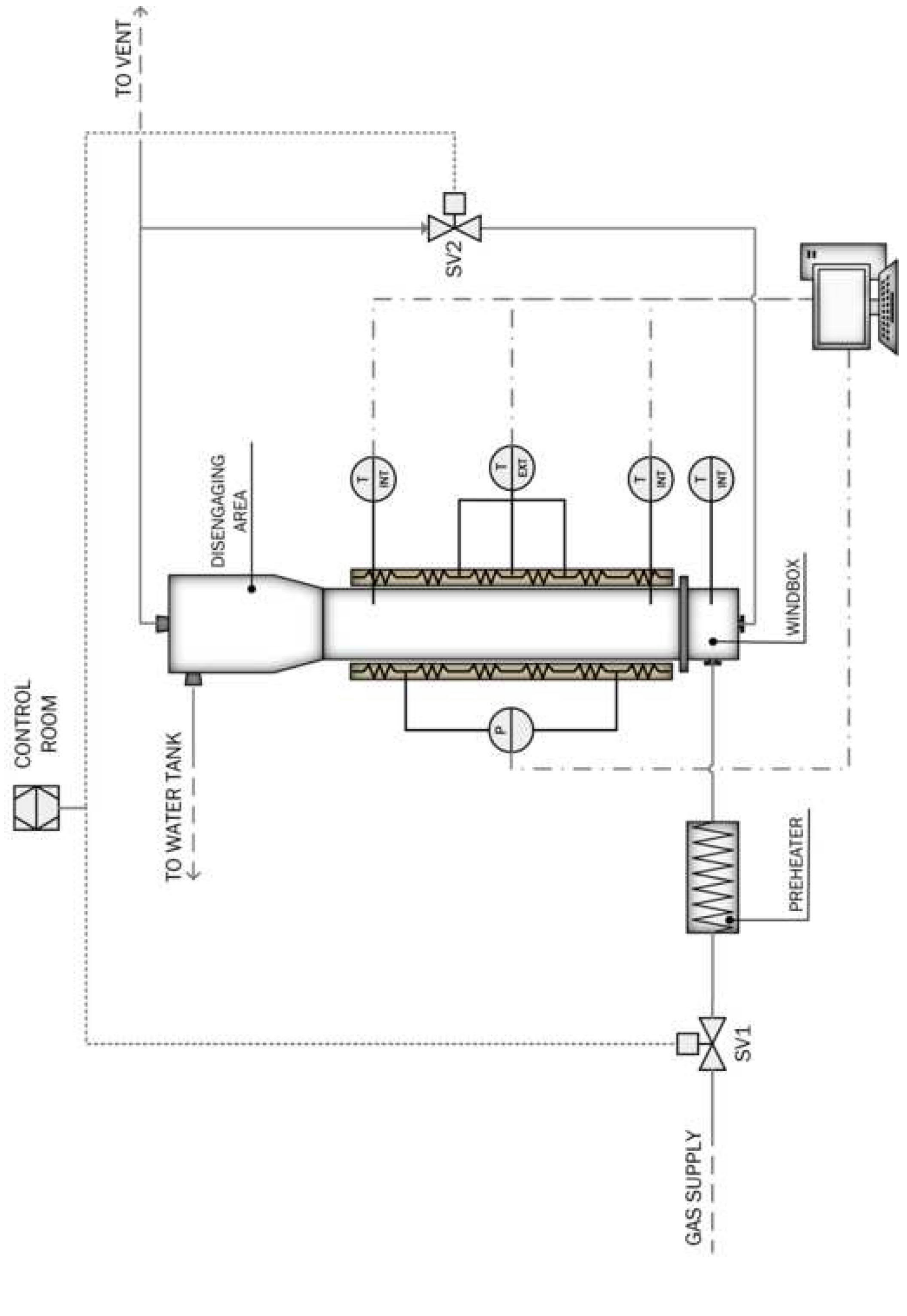


$\square$ Bubble escape $\square$ Hindered Sedimentation $\square$ Solids Consolidation $\square$ Settled bed
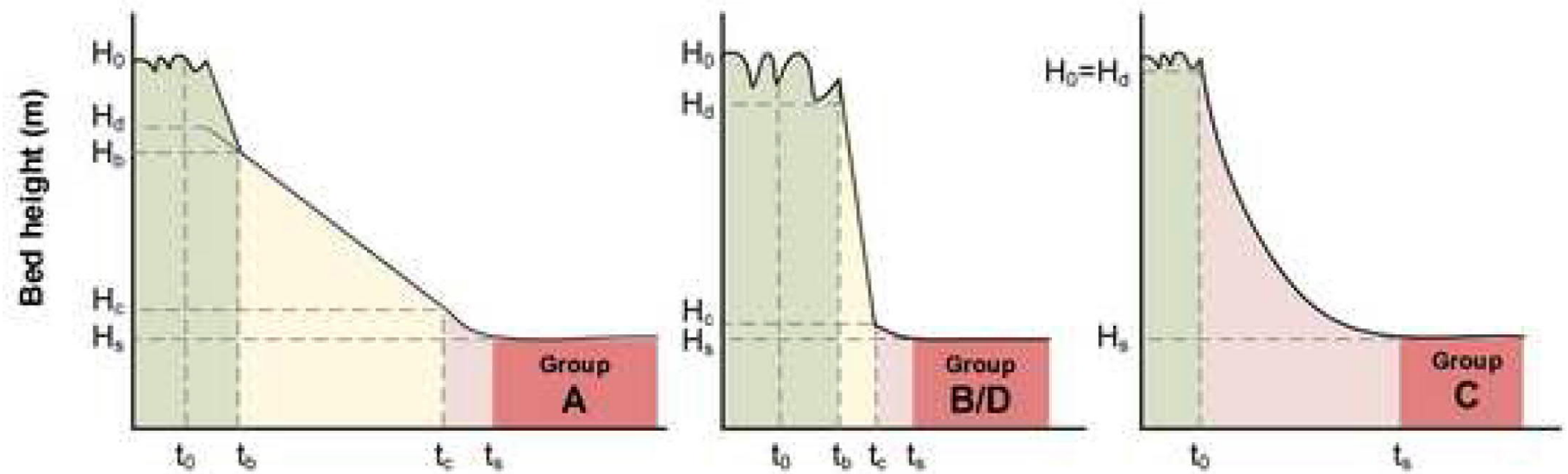

Time (s)
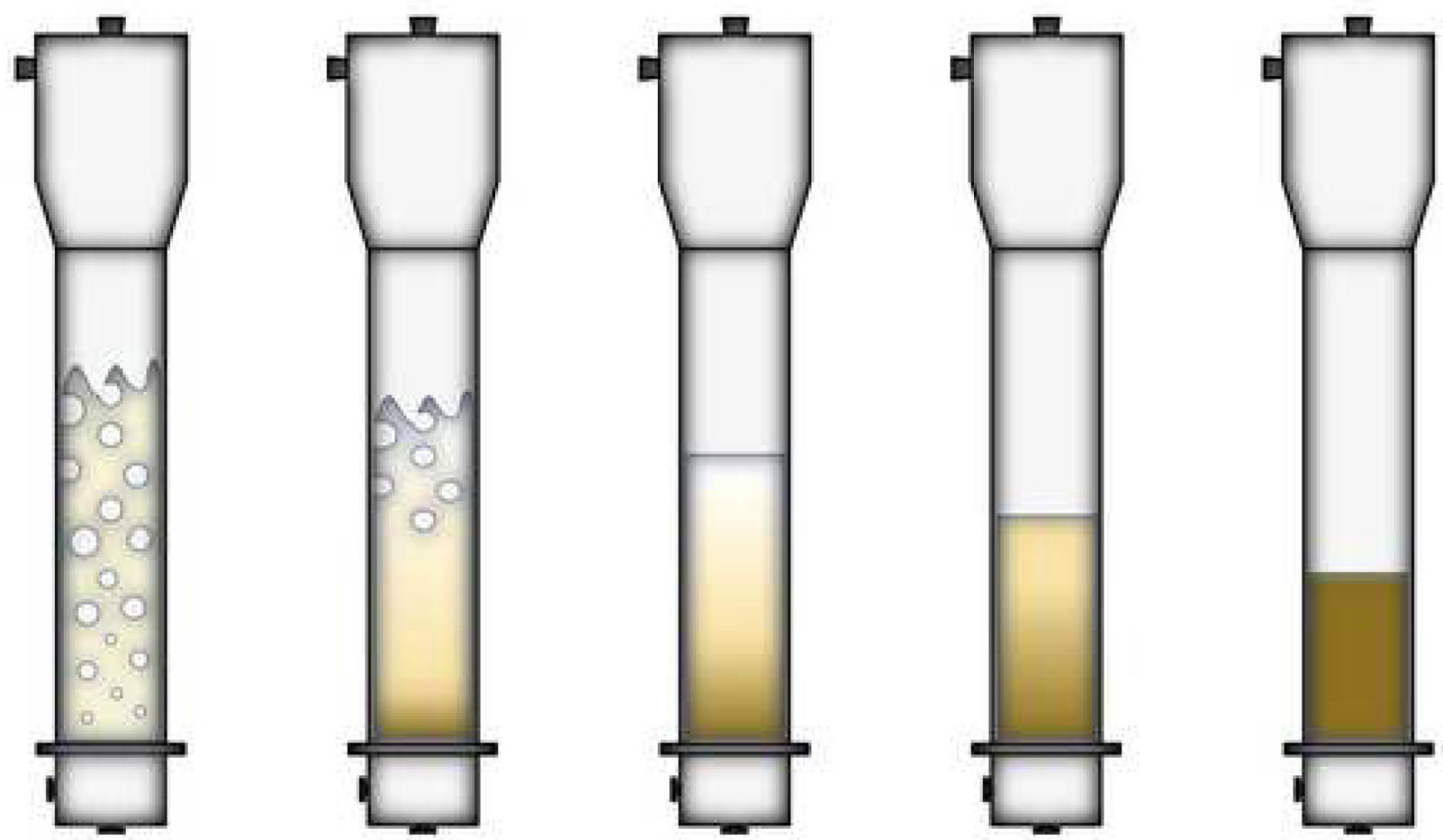

$t<0$

$t<t_{b}$

$t=t_{b}$

t

$t=t_{s}$ 


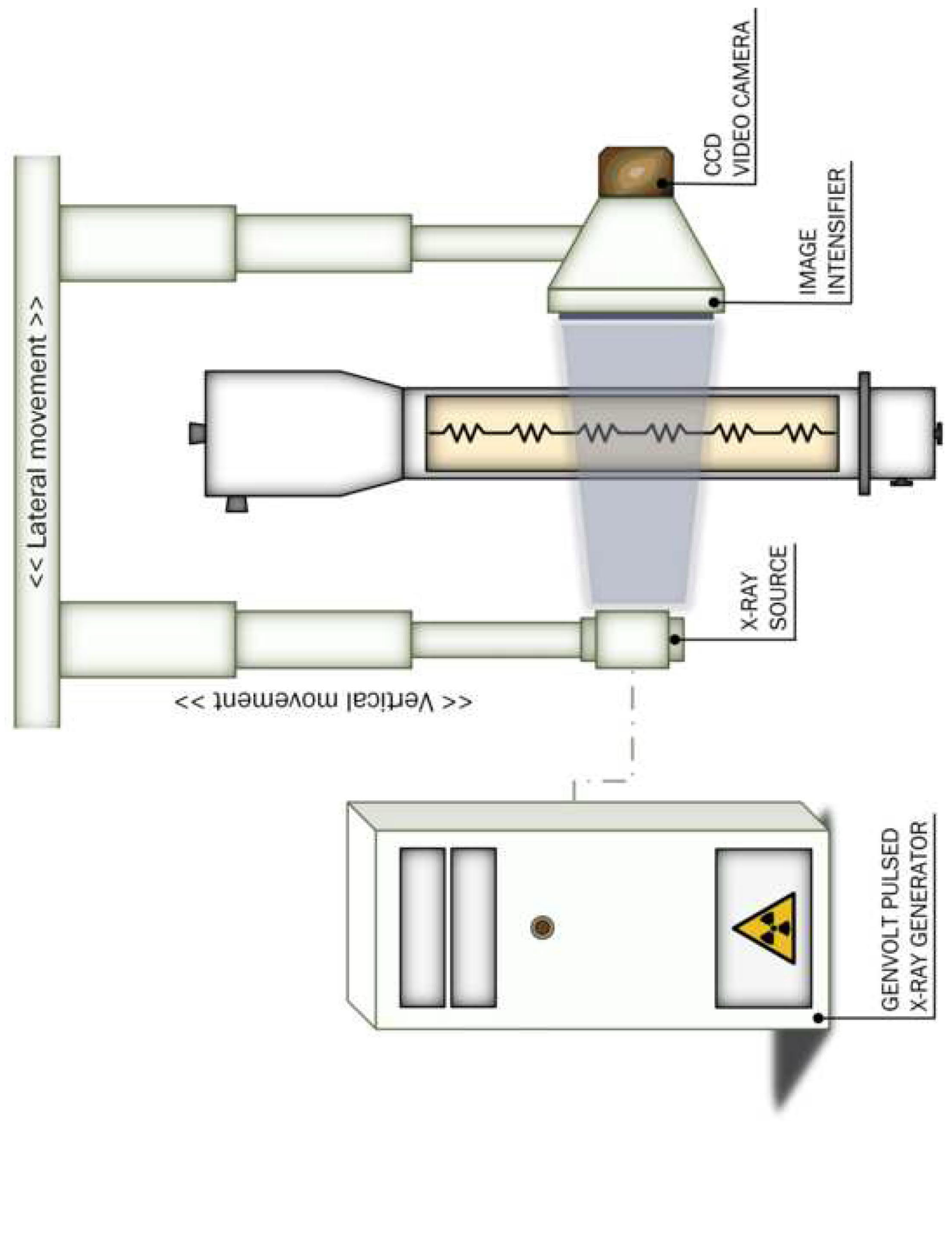




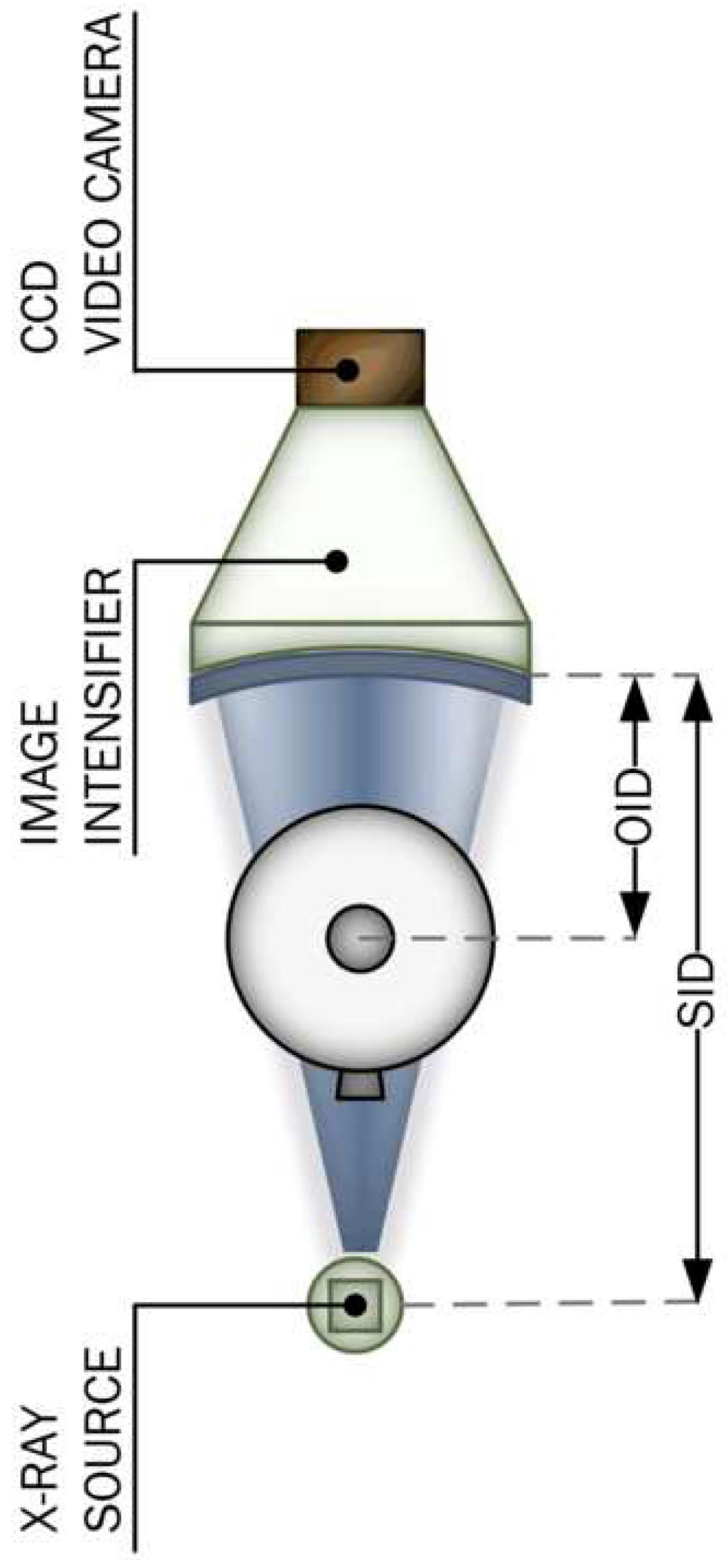

\begin{tabular}{l}
0 \\
\hline \\
\hline
\end{tabular} 

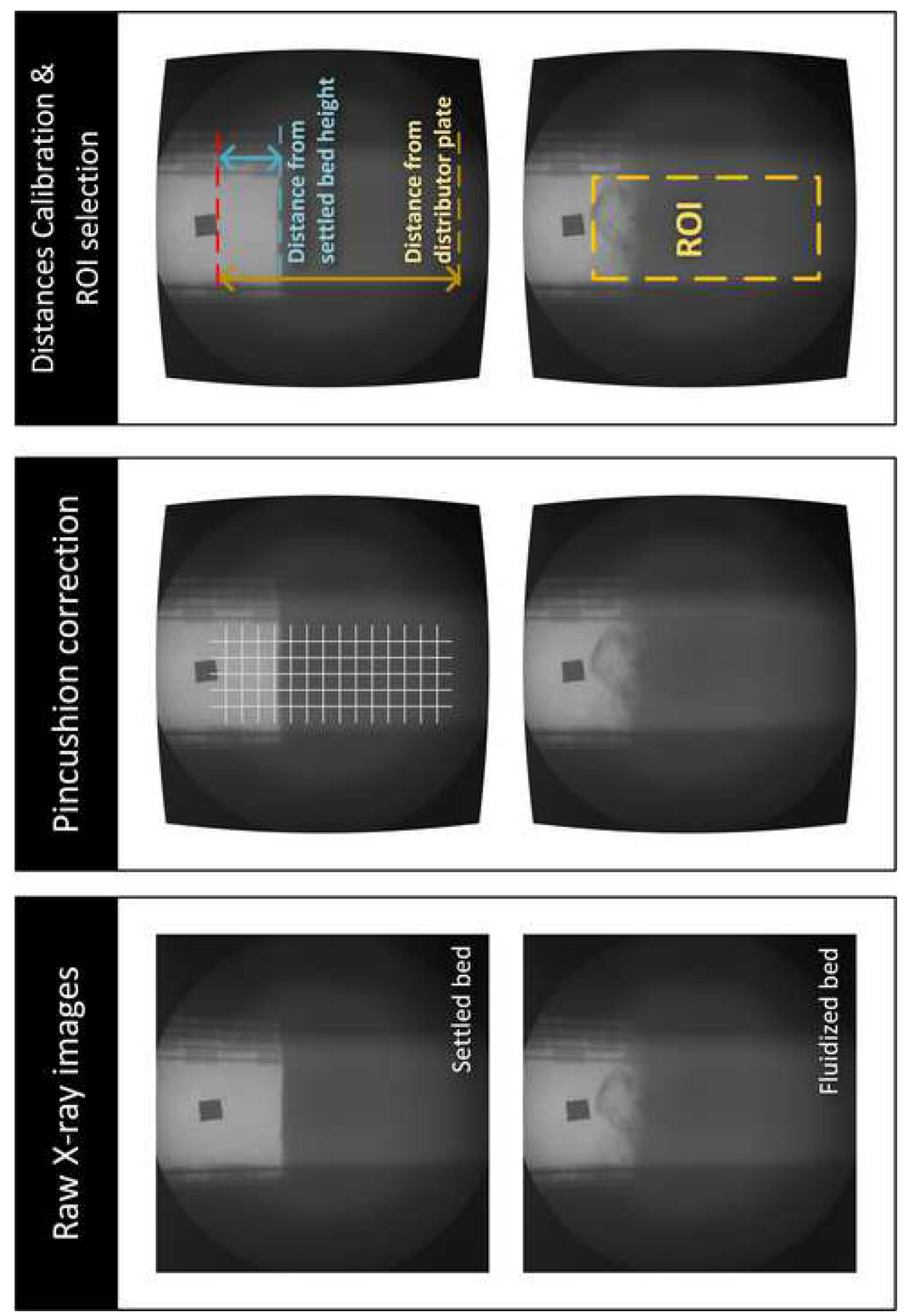

旁 윤 은 

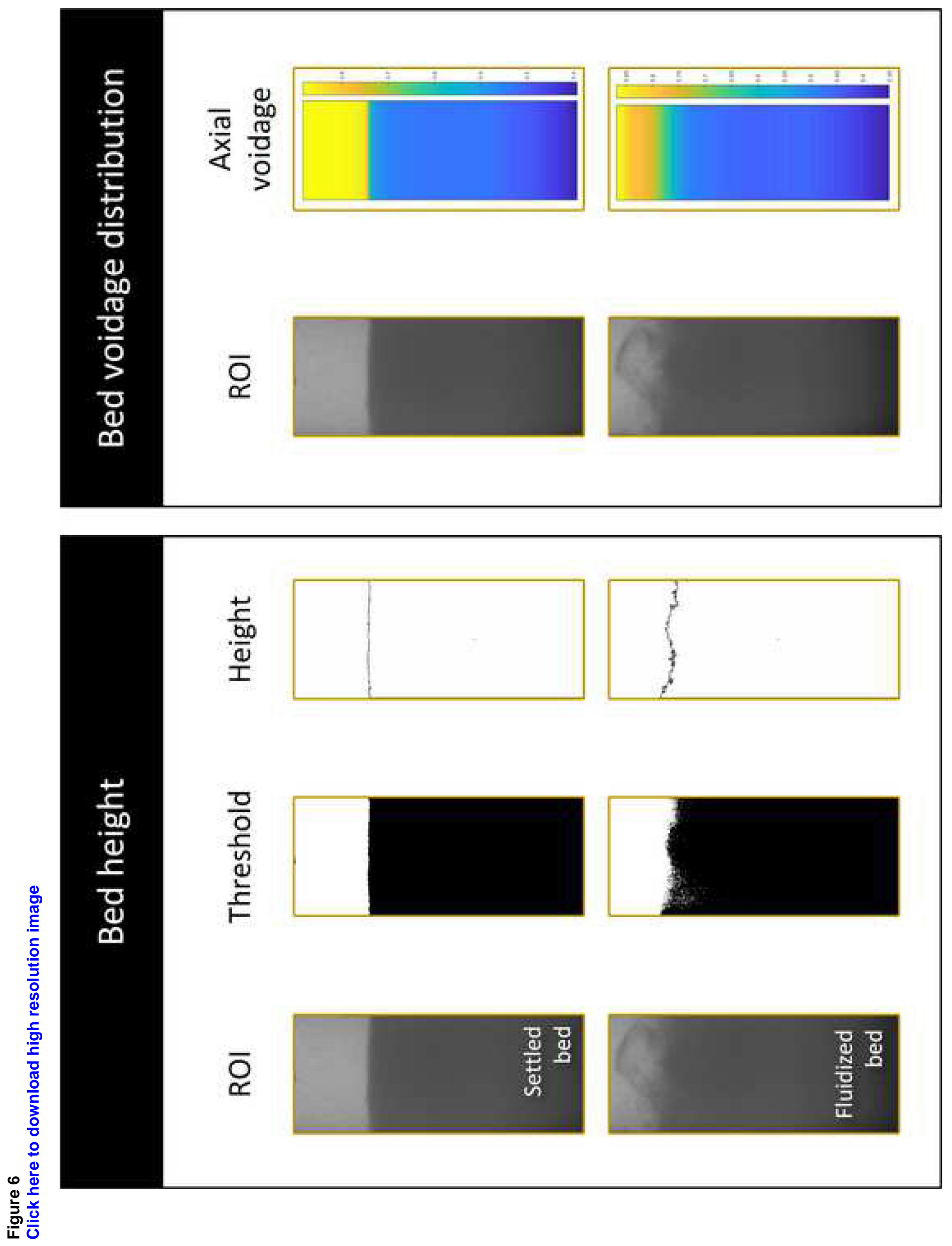

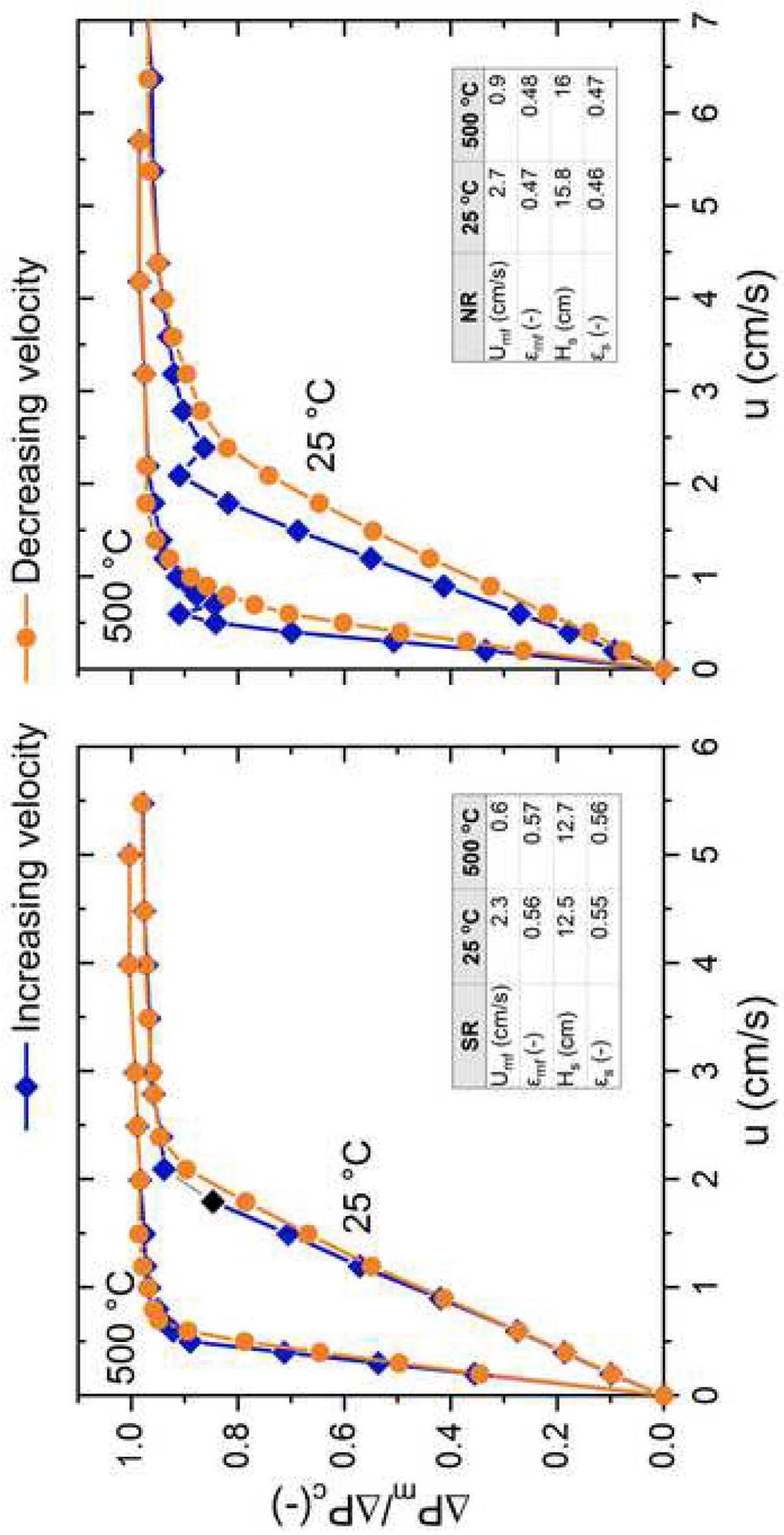

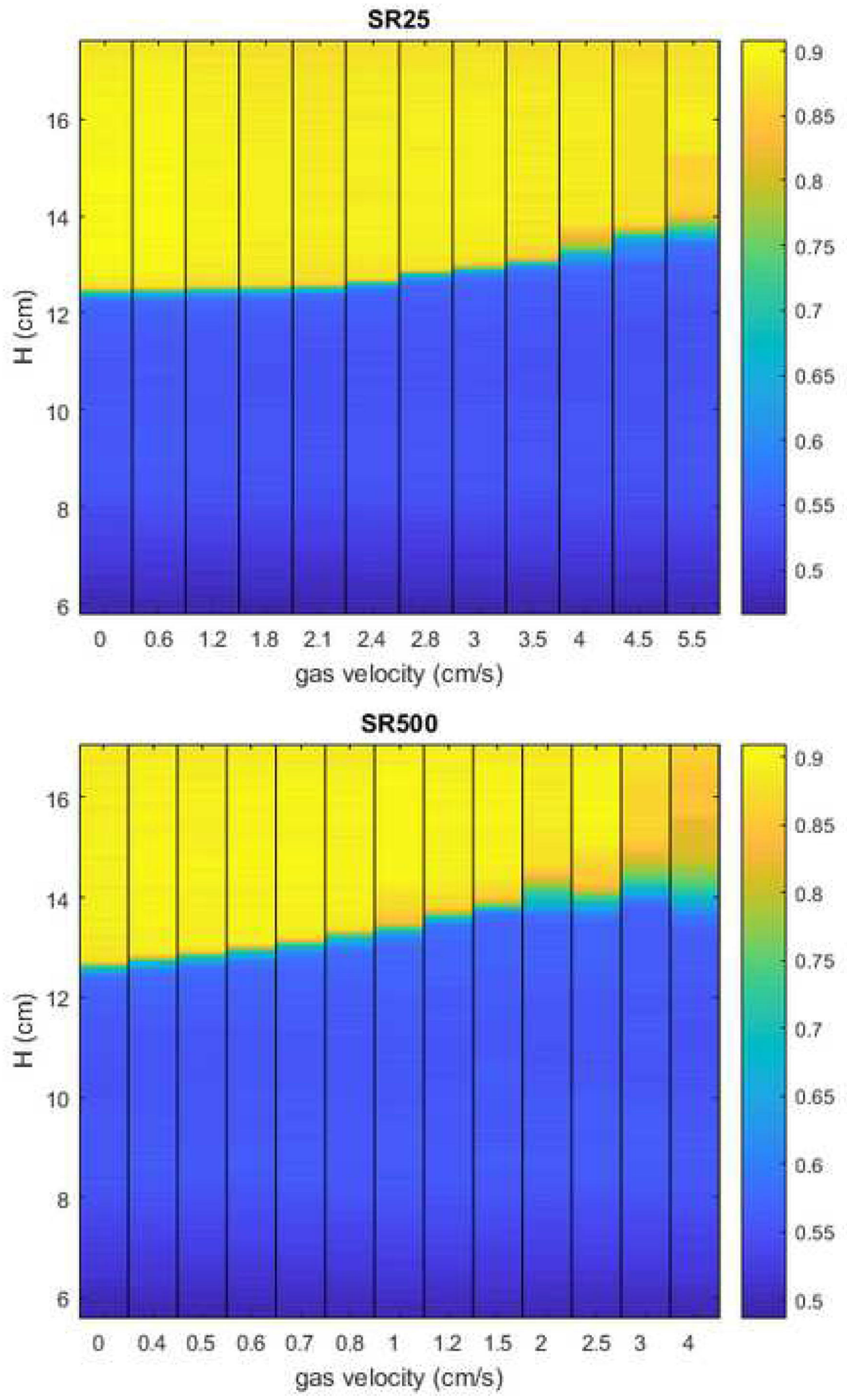
Click here to download high resolution image
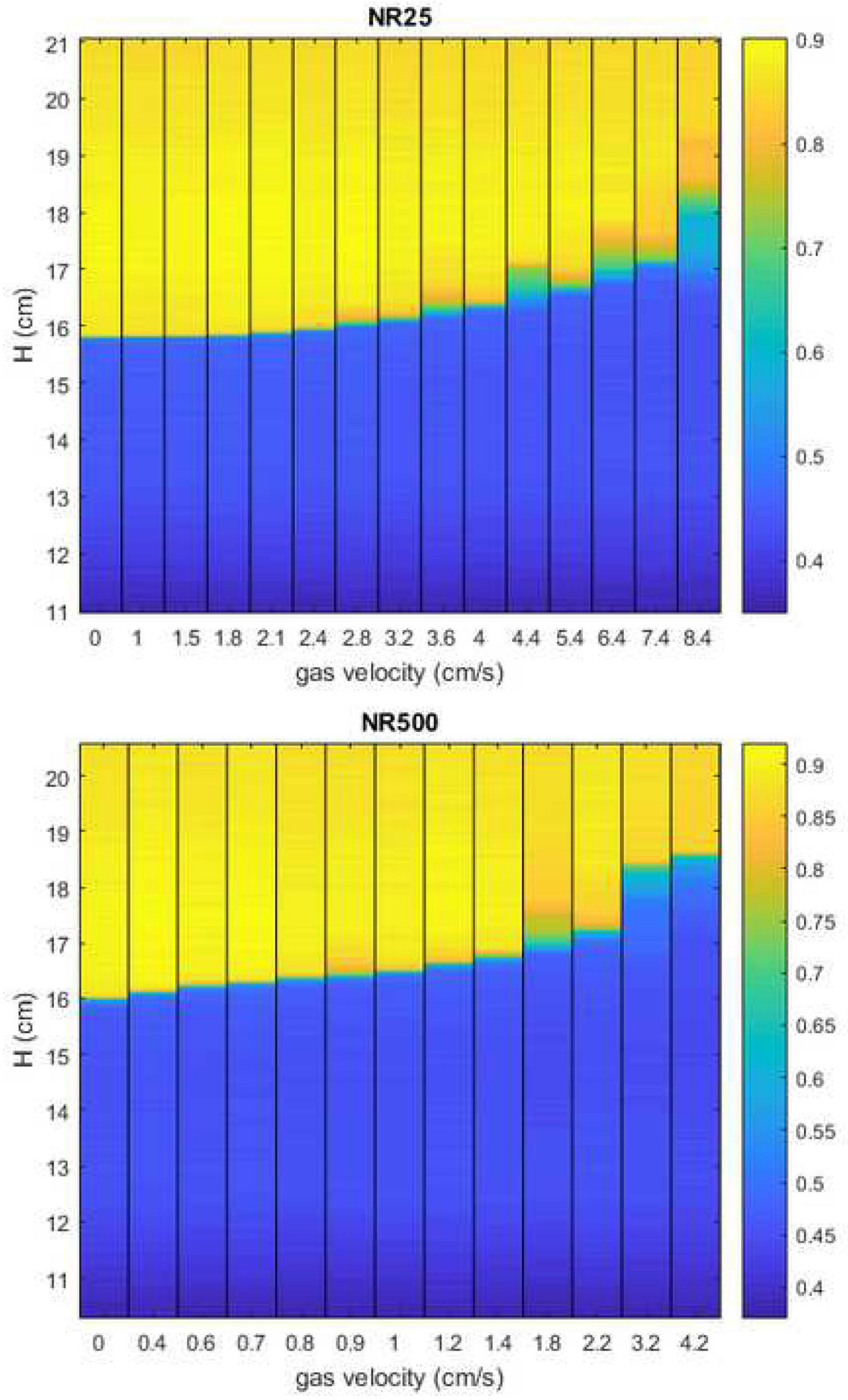

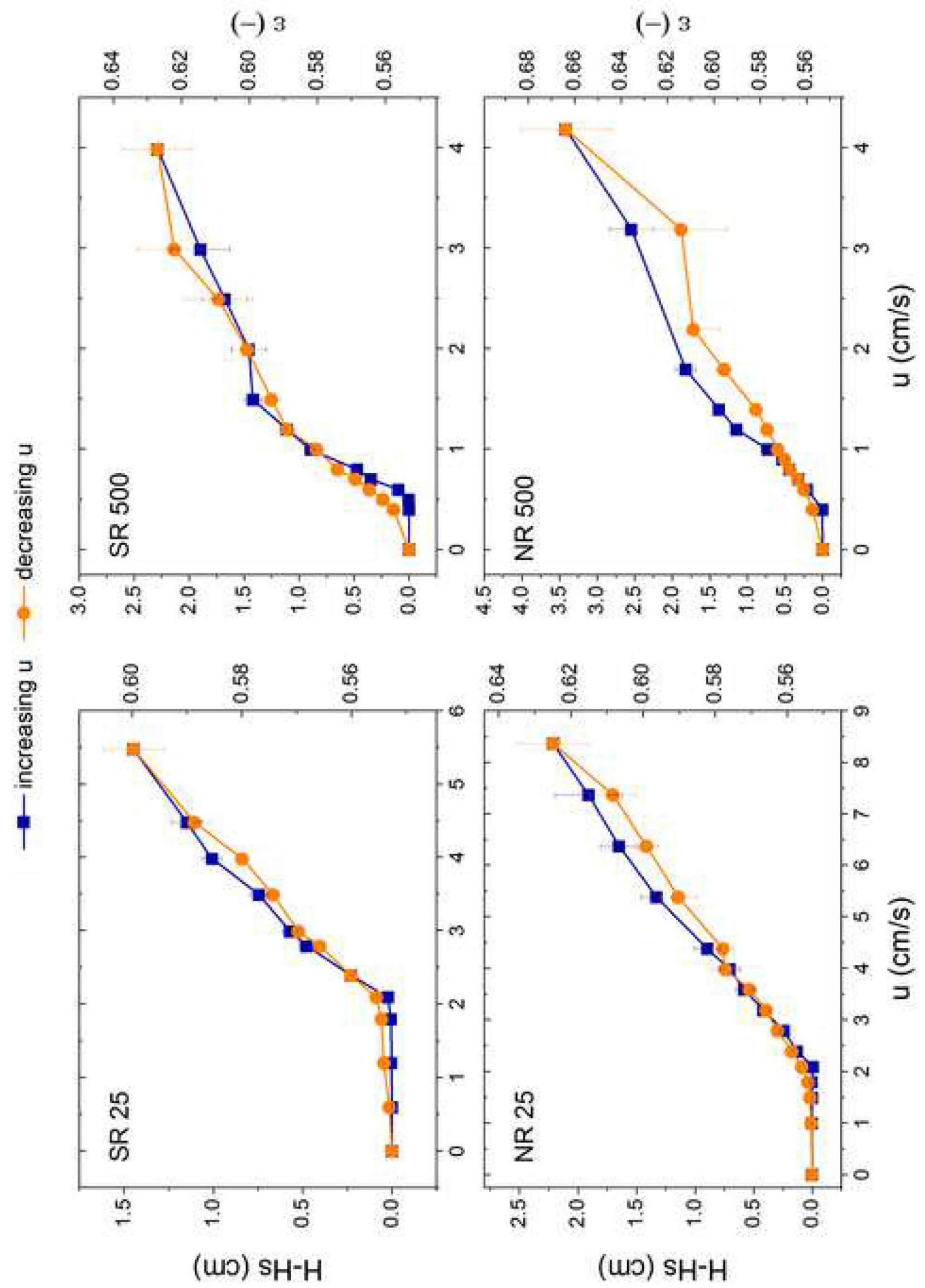

$\infty \frac{\Phi}{d}$ 

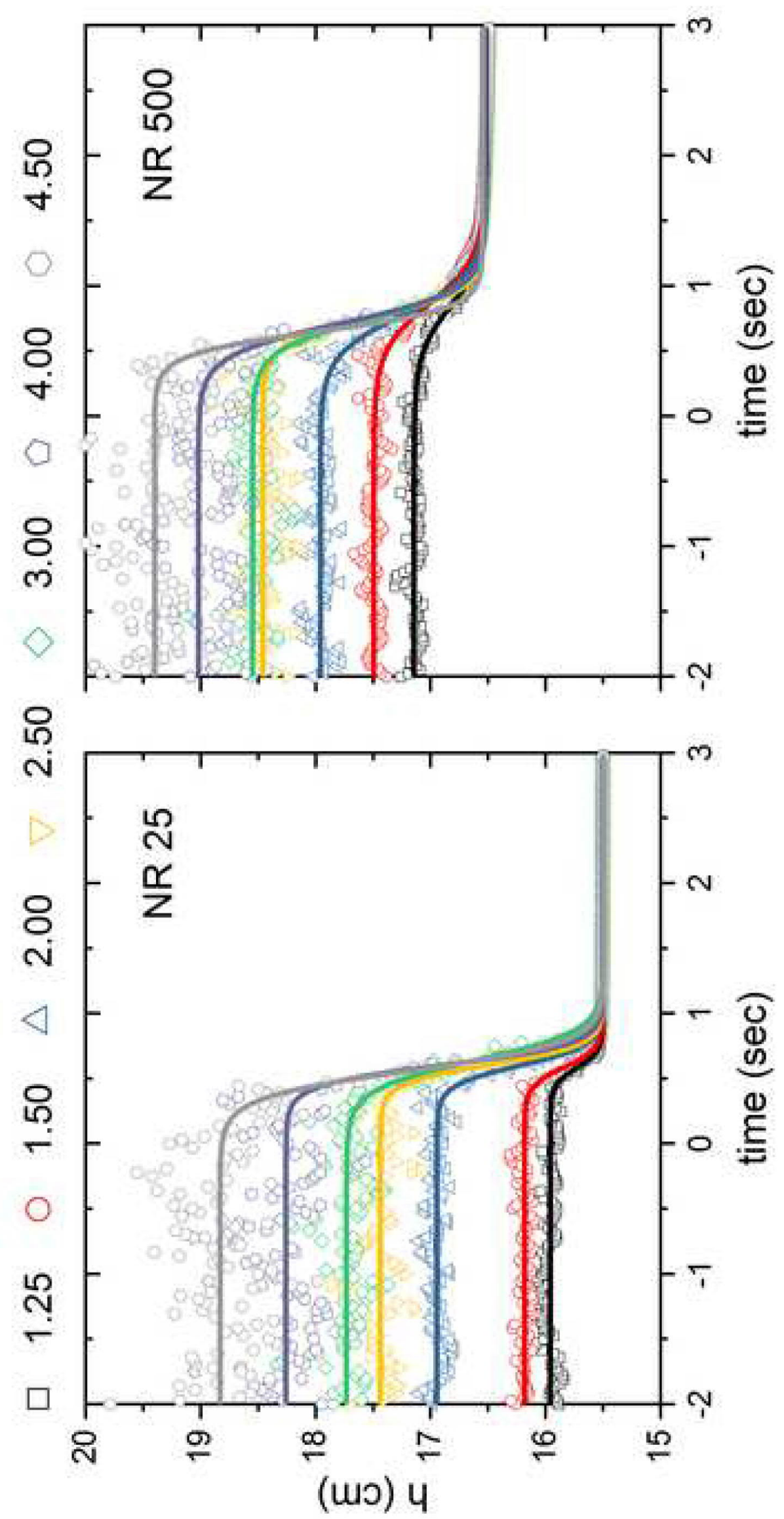

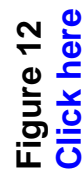



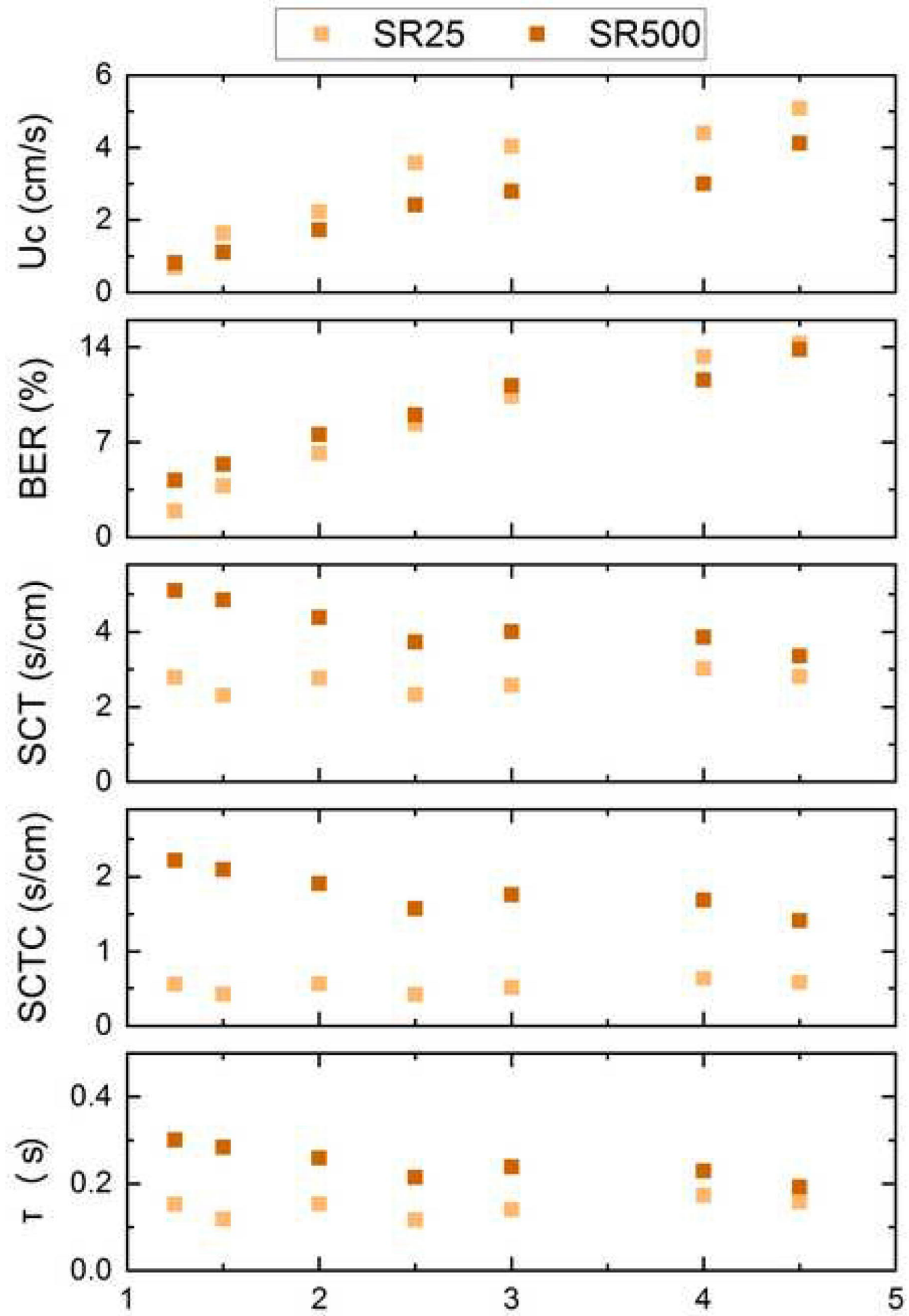

FI (-) 

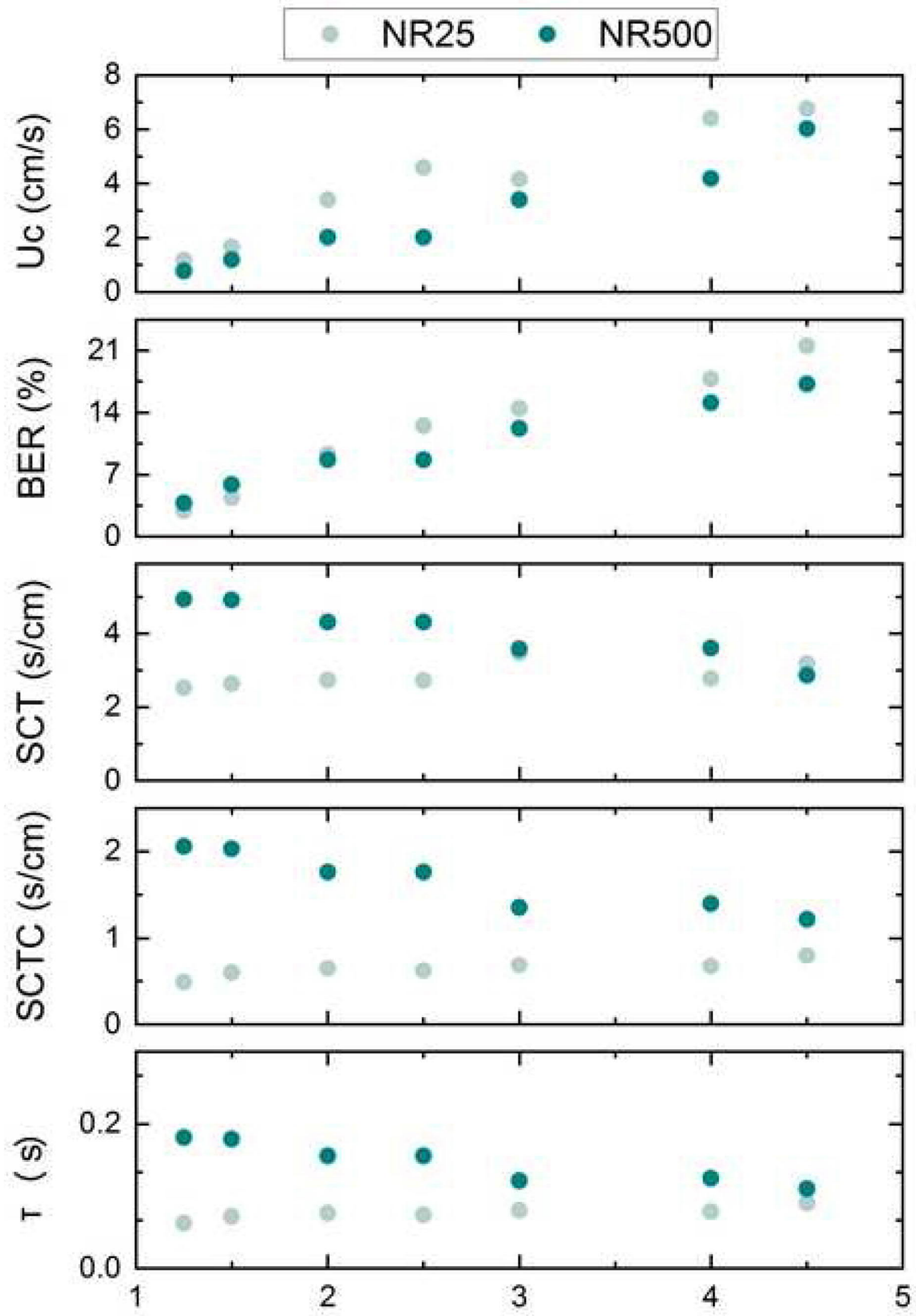

$\mathrm{Fl}(-)$ 
Click here to download high resolution image
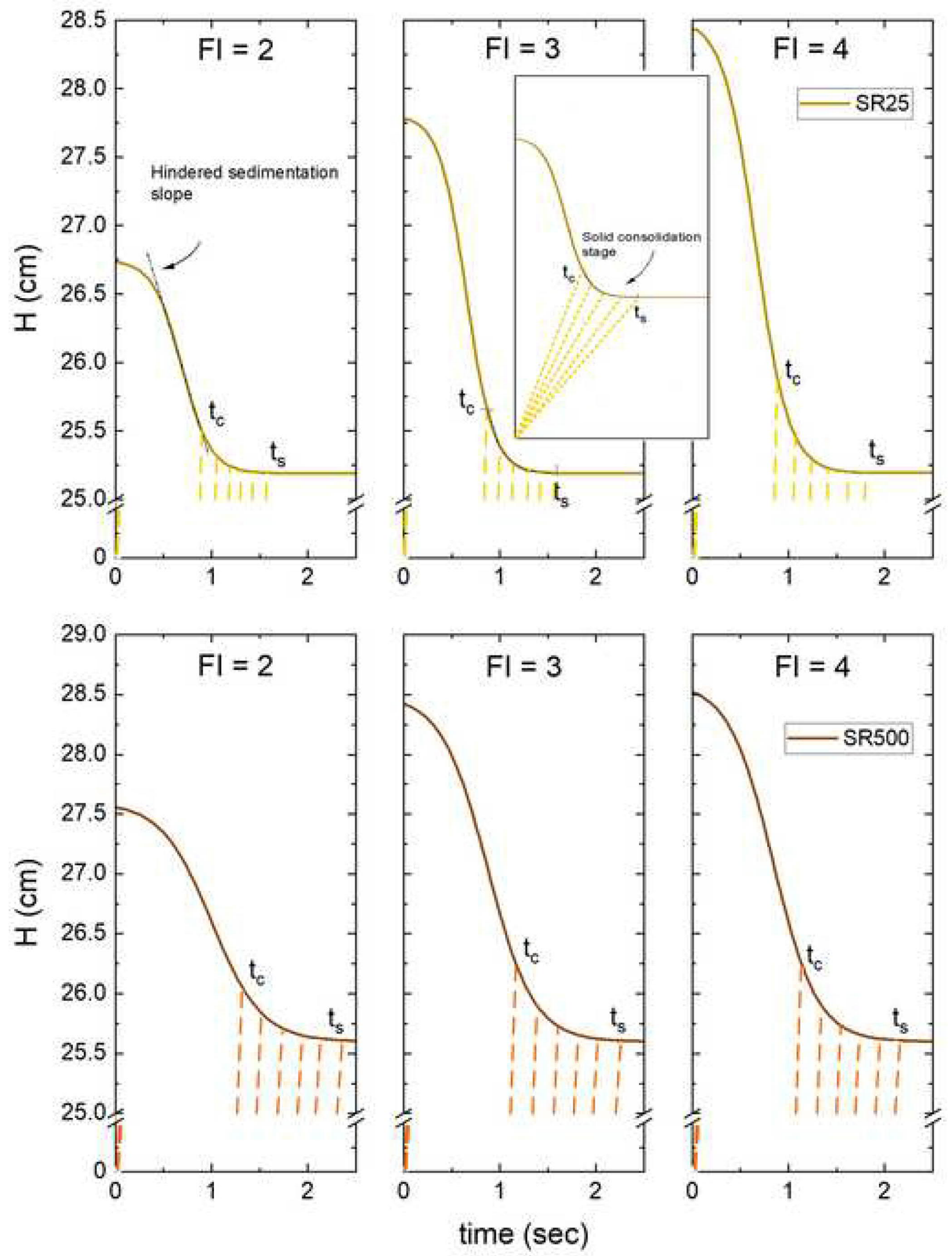


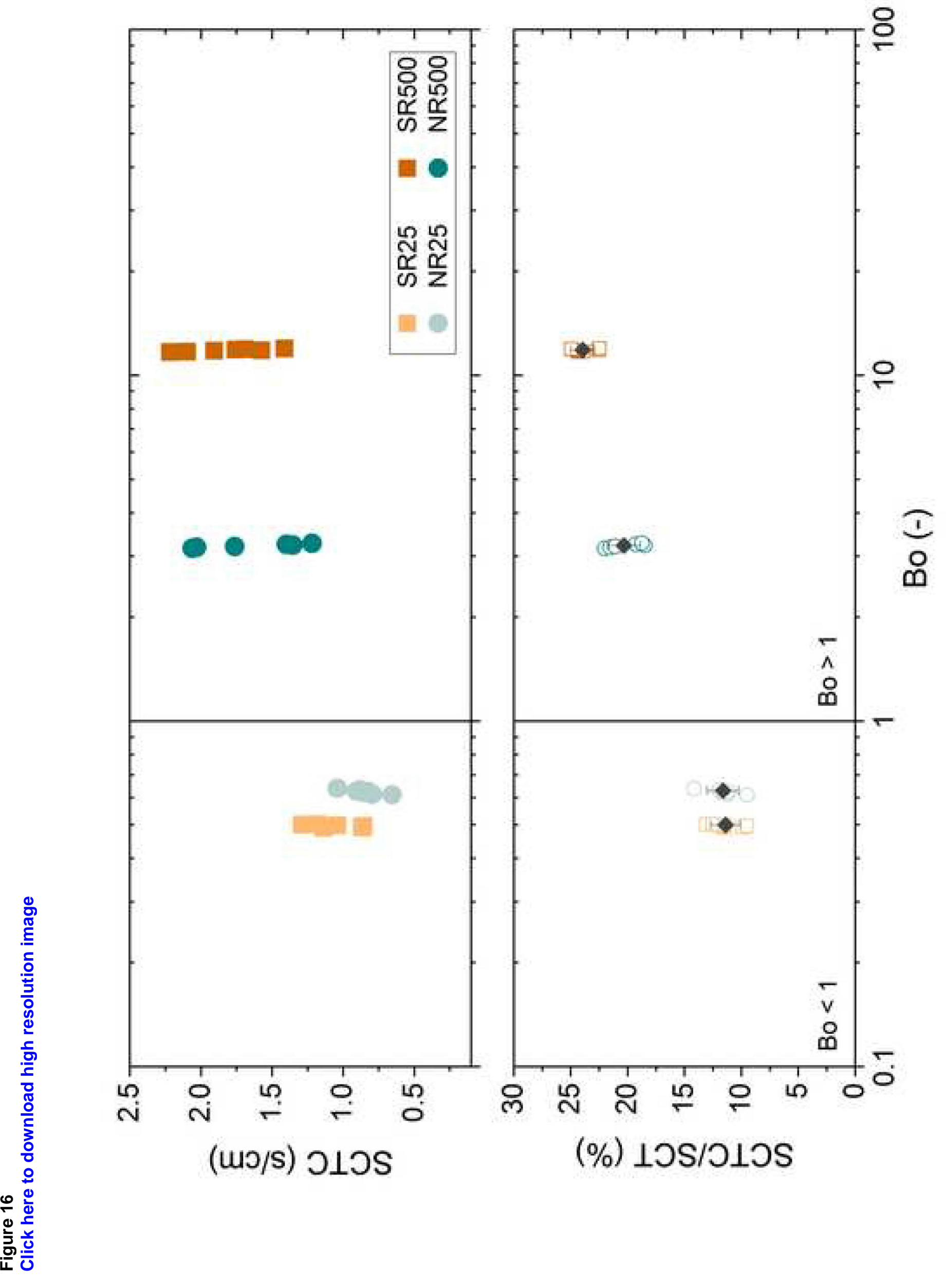

